\title{
Idealized Study on the Effect of Bottom Topography on the Seasonality of the Stability of the Iceland-Faeroe Front
}

\author{
Miguel A. JimÉNEZ-URiAs AND LuANNE ThOMPSON \\ School of Oceanography, University of Washington, Seattle, Washington
}

(Manuscript received 14 March 2018, in final form 10 October 2018)

\begin{abstract}
We investigate the effects of bottom topography on the instability, eddy-driven heat flux, and overturning of a front that sits atop a ridge by varying the initial location of an idealized frontal outcrop with respect to a topographic ridge. The front is periodic in the along-ridge direction and unstable to both mixed layer and mesoscale baroclinic instabilities with both instabilities focused on the northern flank of the ridge where the front outcrops. We find agreement with the theoretical predictions for the development of mesoscale instability of the jet in the presence of sloping bottom topography, and we find the initial growth of surface mixed layer eddies is insensitive to topographic variations. However, during the finite amplitude phase of mixed layer instability, we find faster development of mesoscale eddies and thus a stronger cross-front eddy heat flux and residual circulation for the position of the jet where we found the faster growth of mesoscale baroclinic instability. Over an advective time scale that represents the transit time of a water parcel along the Iceland-Faeroe Ridge (IFR), the resulting eddy heat flux is greatest in the cases where the frontal jet experiences the most destabilizing bottom topography of the three cases tested, with values comparable to the heat flux associated with the mean flow. Therefore, eddy dynamics over the IFR frontal region are important contributors to the heat exchanges between the North Atlantic and Nordic Seas, with the bottom topography playing a key role in determining the largest heat fluxes, whether the initial growth is dominated by mixed layer eddies or mesoscale eddies.
\end{abstract}

\section{Introduction}

The Greenland-Scotland Ridge mediates the exchange of water between the warm and salty subpolar North Atlantic and the cold and relatively fresh Nordic Seas. About half of the total Atlantic inflow into the Nordic Seas takes place between Iceland and the Faeroe Islands (Hansen et al. 2008), where it flows mostly along topographic contours and is associated with the surface-to-bottom Iceland-Faeroe Front (IFF; Hansen and Meincke 1979). The front outcrops to the north of the Iceland-Faeroe Ridge (IFR) crest, the Nordic flank, and provides a pathway for warm and salty Atlantic water to flow along the ridge (Fig. 1). This water then feeds the Faeroe Current, a major branch of the Atlantic inflow that contributes to preconditioning the Nordic Seas for deep convection and the formation of deep overflows, the deepest branch of the Atlantic meridional overturning circulation (Quadfasel and Käse 2013). The front extends to the south of the IFR crest, the

Corresponding author: Miguel Jimenez-Urias, jimenezm@ u.washington.edu
Atlantic flank, where the frontal isopycnals approach the bottom running parallel to the sloping topography. There, the gently sloping isopycnals are maintained by the alongslope gravity current originating from the deep overflow from the Faroe Bank Channel overflow and fed by intermittent cross-IFR overflow (Beaird et al. 2013).

On the Nordic flank of the IFR, away from the Icelandic and Faeroe shelves, the mean location of the IFF is largely constrained by the convergence of the North Atlantic Current with the East Icelandic Current, and by the strong topographic steering, despite the presence of strong eddy variability (Hansen and Meincke 1979; Fox and Maskell 1996). The IFF strongly meanders, shedding both cold- and warm-core eddies that are associated with the nonlinear stages of baroclinic instability (Allen et al. 1994; Miller et al. 1995). The IFF is composed largely of two water masses during summertime, when the majority of the historical observational samplings have taken place (Rossby and Flagg 2012): The warm and salty Atlantic water lies atop the front, with the colder and relatively fresher Nordic seawater lying underneath. During winter, recent observations show an additional water mass that results from freshwater 


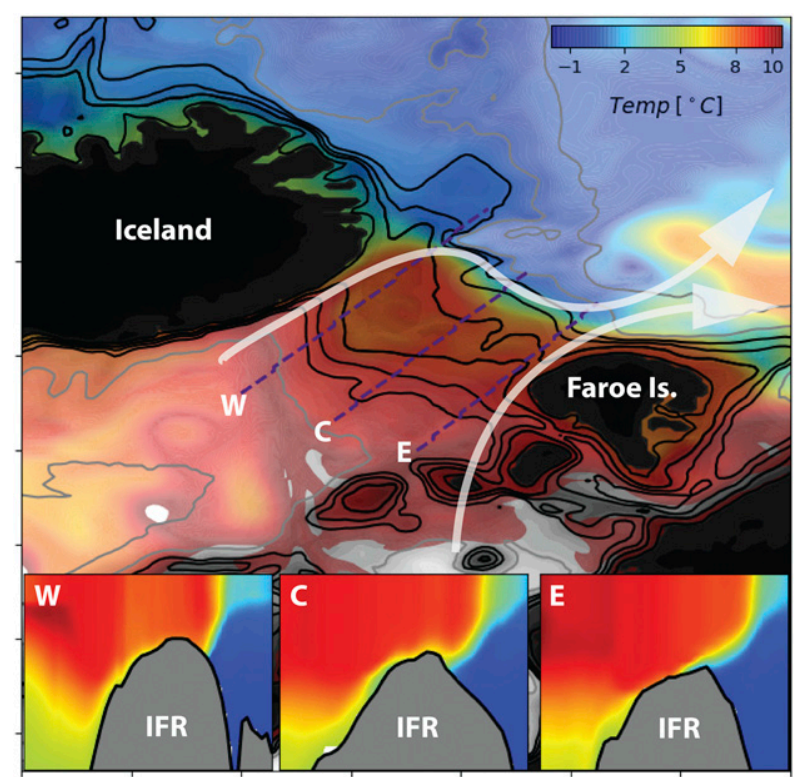

FIG. 1. Potential temperature at a depth of $200 \mathrm{~m}$ from a multiyear, global ocean simulation with $0.10^{\circ}$ horizontal resolution (Small et al. 2014). White arrows represent surface (Atlantic water) pathways of the mean flow into the Nordic Seas across the IFR. The mostly along-ridge isotherms promote an along-ridge geostrophic flow into the Nordic Seas. Dark contours represent topographic contours every $100 \mathrm{~m}$ until $1000 \mathrm{~m}$ and then every $500 \mathrm{~m}$ until a depth of $2500 \mathrm{~m}$. Letters W, C, and E represent the location of across-ridge sections, each displayed at the bottom of the figure.

intrusions associated with mixed layer water from the Nordic Sea side of the front. These anomalies extend across the IFR crest, likely the result of the combined action of the convective homogenization of the front that deepens the mixed layer and subduction by baroclinic instability (Beaird et al. 2016). Thus, there are two possible mechanisms that promote eddy-driven exchange across the IFF. The first is owing to classic mesoscale baroclinic instability whenever mixed layers are shallow, typical of summer conditions. The second is when baroclinic instability within the mixed layer is at work, when sufficiently deep mixed layers also have strong horizontal density gradients.

Recent linear stability studies have shown that when the upper ocean is unstable to mixed layer baroclinic instability, in the presence of flat bottom topography, the resulting mixed layer instability dominates the evolution of the upper ocean (Callies et al. 2016). However, the behavior of mixed layer eddies (MLEs) in the presence of destabilizing bottom topography, both in the linear and nonlinear phases of MLE instability remains unexplored. This has the potential for great relevance to the topographically locked IFF in which along-front variations of topography, such as a steeper frontal slope toward Iceland (Maskell et al. 1992), may determine localized regions where destabilizing effects on mesoscale instability are greatly enhanced and, as a result, can determine complex pathways for eddy-driven exchange and spread of water masses across the frontal region.

In this study we examine the evolution of the instability of an idealized representation of the Iceland-Faeroe Front that reproduces the basic observed features of the region with different representations of the surface front in summer and winter. We build on previous studies of baroclinic instability of ocean fronts in the presence of bottom topography by including a mixed layer front in the presence of variable topography, barotropic shear, and a continuous cross-ridge frontal structure. The paper is organized as follows: first, we introduce the theoretical framework used within our study, namely, classical results from linear baroclinic instability such as ageostrophic and topographic effects in the growth of unstable wave modes. Then we provide a description of the model and describe the two sets of experiments that focus on the seasonality of the stability. We examine topographic effects on the initial growth of the instability associated with each experiment and identify the dominant mechanism of the instability. We then examine the resulting eddy-driven overturning for two contrasting initial configurations of the front, and finally, we discuss the implications for seasonality of eddy-driven exchange across the Iceland-Faeroe Front.

\section{Theoretical framework}

The classical theory that describes the evolution of baroclinic instability is that of quasigeostrophic flows, which describes mesoscale flows with typical length scales $L \sim(10-100) \mathrm{km}$ that grow at typical advective time scales $t \sim O(L / U)$ (Pedlosky 2013a). Baroclinic instability extracts available potential energy from the mean flow by relaxing the otherwise (upward) tilting isopycnals of a background state in thermal wind balance. In recent years, significant developments have taken place that incorporate nonquasigeostrophic effects on the instability process, of which we present a short outline below.

We begin with a description on the effects bottom topography has on the mesoscale baroclinic instability. In both the canonical Eady and (bottom) Charney models (Vallis 2017), sloping bottom topography can modify the instability when the depth scale of influence of the unstable modes is large enough so that Rossby waves are able to mutually reinforce in the first place (Lozier and Reed 2005; Pedlosky 2013b). For the Eady model, Blumsack and Gierasch (1972) derived the growth rates for unstable modes that incorporate the effects of (linearly) sloping bottom topography and found that, given $\gamma=-h_{y} /\left(\bar{\rho}_{y} / \bar{\rho}_{z}\right)$, the ratio between 


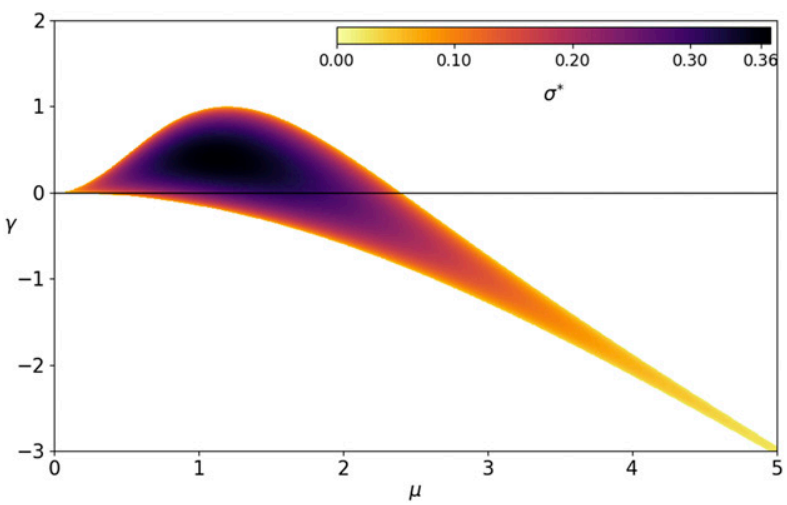

FIG. 2. Theoretical growth rate for the Eady model as a function of topographic parameter $\gamma$, where $\gamma>0$ represents the case where bottom topography slopes similarly as isopycnals, and $\gamma<0$ when topography slopes in the opposite direction as isopycnals. From Hetland (2017).

topographic slopes and (mean) isopycnal slopes $\gamma \geq 1$ stabilizes the system to baroclinic instability. Sloping topography with a negative slope parameter $\gamma<0$ (tilting in an opposite direction to the isopycnal tilt), on the other hand, always promotes a destabilizing effect (Fig. 2). Furthermore, bottom topography destabilizes a flow (compared to the flat bottom case) when $0<\gamma<1$, that is, isopycnals slope in the same direction as bottom topography. This situation resembles that of the Atlantic side of the IFR (south of the crest), although this region is characterized by having slope ratio $\gamma \approx 1$ (Beaird et al. 2013). The range $\gamma<0$ is more stable (compared to the flat bottom case) and resembles that of coastal upwelling shelf break fronts and the outcropping front north of the IFR crest (Flagg and Beardsley 1978; Barth 1989; Maskell et al. 1992; Lozier and Reed 2005; Isachsen 2011; Beaird et al. 2013, 2016).

Concerned about the limiting quasigeostrophic scalings, Boss et al. (1996) studied the stability of outcropping density fronts using the formalism of potential vorticity (PV) fronts in two layers, allowing them to cast the instability growth rate as a function of the ratio of layer stratification. They calculate the growth rate of baroclinic instability for any two-layer, shallow-water model with a jet of finite horizontal extent and found that the layer thickness ratio greatly affects the most unstable modes; it gets reduced by changes in layer thickness with respect to the total bottom depth. In addition, they also found evidence of a surface-trapped ageostrophic baroclinic instability that results from a resonant interaction between a surface gravity wave and a Rossby wave, but found that quasigeostrophic results within their study were robust and that the outcropping of layer PV fronts was consistent with the quasigeostrophic interpretation of PV delta sheets.
In recent years, there has been a shift of attention toward the submesoscales, characterized by length scales $L \sim O(1-10) \mathrm{km}$ and time scales $t \sim O\left(f^{-1}\right)$, motivated by wintertime mixed layer fronts that become unstable to baroclinic instability (Boccaletti et al. 2007). This regime greatly departs from the quasigeostrophy by the vanishingly small vertical stratification and a lateral density gradient in thermal wind balance, such that $N_{\mathrm{ML}}^{2} \sim S_{\mathrm{ML}}^{4} / f^{2}$, or in terms of nondimensional parameters $\mathrm{Ri}_{\mathrm{ML}}=N_{\mathrm{ML}}^{2} f^{2} / S_{\mathrm{ML}}^{4} \sim O(1)$, where $N_{\mathrm{ML}}^{2}=g \alpha T_{z}$ and $S_{\mathrm{ML}}^{2}=-g \alpha T_{y}$ represent the vertical and lateral stratification (quasigeostrophy requires $\mathrm{Ri} \gg 1$, where $\mathrm{Ri}$ is the Richardson number). Such conditions arise from the gravitational adjustment of a lateral density gradient within the mixed layer, promoted from either (or both) a laterally inhomogeneous, destabilizing surface forcing (Tandon and Garrett 1994, 1995) or a homogeneous surface forcing in the presence of a preexistent lateral temperature gradient, for example, a large-scale surface front.

Surface mixed layer fronts usually rest atop a tilting pycnocline (e.g., the sloping IFF), that acts as a lower boundary with similar destabilizing effect on the instability as sloping topography at the mesoscales (Boccaletti et al. 2007). Nonetheless, the growth rates and length scales of the most unstable modes are largely determined by the mixed layer Richardson and Burger numbers $\mathrm{Bu}_{\mathrm{ML}}=\left(\mathrm{Rd}_{\mathrm{ML}} / L_{\mathrm{ML}}\right)^{2} \ll 1$ (Stone 1966; Eldevik and Dysthe 2002), given respectively by

$$
\sigma=f\left(\frac{5 / 54}{1+\mathrm{Ri}_{\mathrm{ML}}+\mathrm{Ri}_{\mathrm{ML}} \mathrm{Bu}_{\mathrm{ML}}}\right)^{1 / 2}
$$

with the most unstable length scale given by

$$
\lambda=\phi_{0} \operatorname{Rd}_{\mathrm{ML}}\left(1+\frac{1}{\mathrm{Ri}_{\mathrm{ML}}}+\frac{\mathrm{Bu}_{\mathrm{ML}}}{2}\right)^{1 / 2}
$$

with $\phi_{0}=4 \pi / \sqrt{10}$ and where $\mathrm{Rd}_{\mathrm{ML}}$ is the deformation radius. Most recently, it has been shown that bottom topography can suppress bottom mixed layer baroclinic instability, in particular when the width of the plume is narrow compared the deformation radius (Hetland 2017), and further pushing toward nonquasigeostrophic effects, weakly stratified bottom boundary layers can support mixed layer baroclinic instability, which can lead to enhanced cross-slope transport through the boundary layer (Wenegrat et al. 2018).

\section{Model configuration}

We use the Regional Ocean Modeling System (ROMS; Shchepetkin and McWilliams 2005) that solves the primitive 


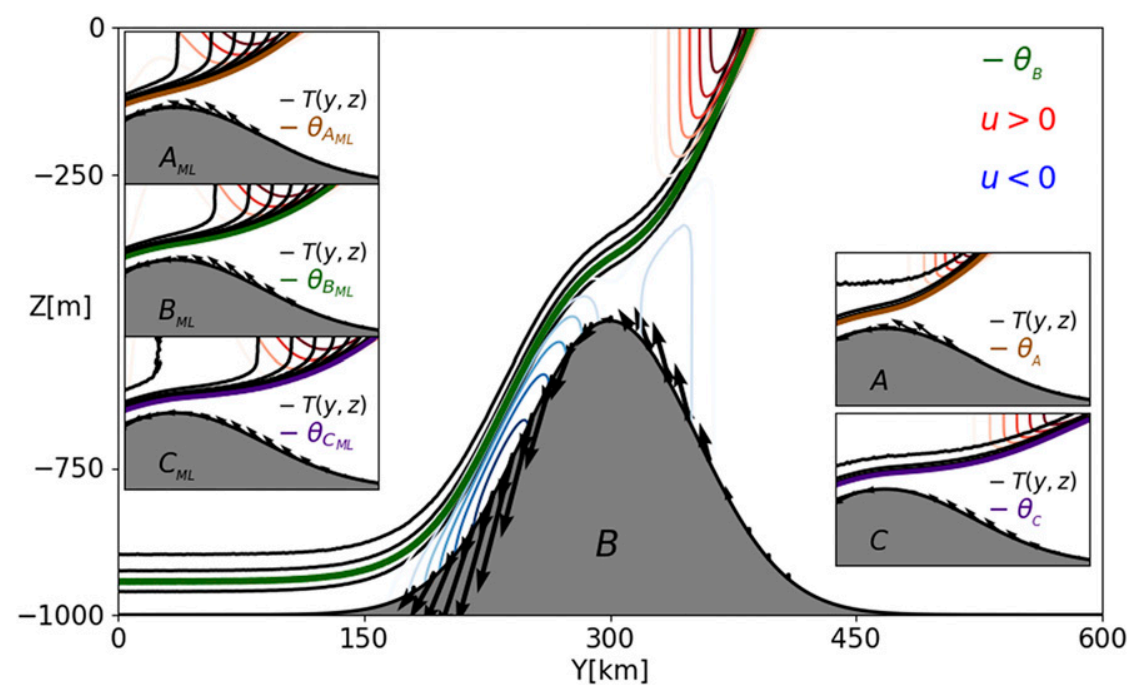

FIG. 3. Initial distribution of zonal velocity (red and blue contours) and temperature (black contours) for experiments with no mixed layer front $\{\mathrm{A}, \mathrm{B}, \mathrm{C}\}$, and those with a mixed layer front $\left\{\mathrm{A}_{\mathrm{ML}}, \mathrm{B}_{\mathrm{ML}}, \mathrm{C}_{\mathrm{ML}}\right\}$. The (outcropping) thermocline $\theta$ for each experiment is shown as a thick colored contour, and its spatial range and location with respect to the bottom topography is identical in experiments $\mathrm{A}$ and $A_{\mathrm{ML}}\left(\theta_{A}\right.$, gold contour), in $\mathrm{B}$ and $\mathrm{B}_{\mathrm{ML}}\left(\theta_{B}\right.$, green contour $)$ and in $\mathrm{C}$ and $\mathrm{C}_{\mathrm{ML}}\left(\theta_{C}\right.$, purple contour). Temperature contours are plotted every $0.5^{\circ} \mathrm{C}$, and the black arrows represent the cross-ridge frictional bottom transport $V_{\mathrm{EK}}$.

equations using a terrain-following sigma coordinate. The vertical coordinate stretching results from the presence of a topographic ridge $h=h(y)$ such that the maximum depth is $1000 \mathrm{~m}$ away from topography and the minimum is $500 \mathrm{~m}$ at the crest of the ridge (see the appendix for the analytical configuration). This promotes a vertical resolution $\Delta z$ that varies between 2 and $15 \mathrm{~m}$ atop the ridge, with the higher resolution near the top and bottom boundaries. The channel domain has horizontal dimensions of $L_{x}=250 \mathrm{~km}$ in the zonal $x$ (or equivalently along ridge) direction, and by $L_{y}=600 \mathrm{~km}$ in the meridional $y$ (or equivalently cross ridge) direction. The horizontal resolution is $\Delta x \approx \Delta y \approx 1 \mathrm{~km}$. We use a horizontal (harmonic) viscous dissipation on both temperature $\left(\kappa_{h}=15 \mathrm{~m}^{2} \mathrm{~s}\right)$ and momentum $\left(\nu_{h}=25 \mathrm{~m}^{2} \mathrm{~s}\right)$, and vertical diffusivities $\nu_{v}=3 \times 10^{-3} \mathrm{~m}^{2} \mathrm{~s}$ and $\kappa_{v}=10^{-5} \mathrm{~m}^{2} \mathrm{~s}$.

Throughout all the experiments we use the $f$-plane approximation with $f=1.25 \times 10^{-4} \mathrm{~s}^{-1}$ and use the linear equation of state with density given by $\rho=$ $\rho_{0}\left\{1-g \alpha\left[T(x, y, z, t)-T_{0}\right]\right\}$, where $T$ is the temperature and $T_{0}$ is a reference (constant) value, $g=9.81 \mathrm{~m} \mathrm{~s}^{-2}$ is gravity, and $\alpha=1.7 \times 10^{-4} \mathrm{~K}^{-1}$ is the coefficient for thermal expansion. All the simulations are unforced in order to focus on the initial development of baroclinic instabilities and their effect on the mean flow.

The initial conditions are characterized by a zonal jet in thermal wind balance with a temperature front $T(y, z)$ (see the appendix for the analytical configuration). The temperature front is characterized by the presence of a top to bottom outcropping thermocline $\theta(y, z)$, defined as the temperature range where the magnitude of the temperature gradient is maximum at each point $(y, z)$. For all simulations, the initialization is done in two steps. First, the initial configuration of a flow in thermal wind balance $u=u(y, z)$ is spun up for a period of 30 days in order to develop an Ekman flow due to the model's no-slip bottom boundary condition. Second, we take the time-average of the horizontal velocities and temperature over the second half of the spun-up period, and we add to the temperature unbalanced small amplitude (spatially) random perturbations with amplitude $T_{p}= \pm 0.2^{\circ} \mathrm{C}$.

We perform two sets of simulations each consisting of three experiments. In the first set, with experiments denoted as $\{\mathrm{A}, \mathrm{B}, \mathrm{C}\}$, we focus on the instability of the jet in thermal wind balance with a large-scale temperature front described in the previous paragraph (Fig. 3). In this configuration, eddies that grow from the instability of the jet can adiabatically flux heat across the front, a direct eddy-driven exchange between the cold Nordic waters and the warm North Atlantic. The main difference between the three experiments is that the initial jet in thermal wind balance with the temperature front is progressively shifted toward deeper waters, that is, we vary the position of the jet along the topographic slope. The slope of the frontal thermocline $z_{\theta}$ remains fixed, but the different topographic slope below the jet results in different slope parameter, that is, $\gamma_{\mathrm{NO}}$ becomes 
TABLE 1. Parameters of the frontal jet in thermal wind balance with the temperature front. Subscript "NO" means the variable has been averaged on the Nordic flank of the ridge, over the whole vertical column but with a lateral extension determined by the condition on the bottom flow: $\bar{u} \geq 0.75 u_{\max }$ (except $u_{\max }$, which represents the maximum velocity over such area).

\begin{tabular}{ccccccccc}
\hline \hline Experiment & $Q_{\mathrm{OV}}(\mathrm{Sv})$ & $Q_{\mathrm{FB}}(\mathrm{Sv})$ & $N_{\mathrm{NO}}^{2}\left(10^{-6}\right)$ & $u_{\max _{\mathrm{NO}}}\left(\mathrm{m} \mathrm{s}^{-1}\right)$ & $|\mathrm{Ro}|_{\max }$ & $h_{y_{\mathrm{NO}}}\left(10^{-3}\right)$ & $\gamma_{\mathrm{NO}}$ & $\sigma(\mathrm{day}$ \\
\hline $\mathrm{A}$ & 3.05 & 2.85 & 10.2 & 0.6 & 0.12 & -3.48 & -0.74 \\
$\mathrm{~B}$ & 3.05 & 2.95 & 9.02 & 0.42 & 0.075 & -4.16 & -0.88 & 0.386 \\
$\mathrm{C}$ & 2.7 & 3.19 & 6.42 & 0.34 & 0.04 & -4.85 & -1.04 \\
$\mathrm{~A}_{\mathrm{ML}}$ & 4.1 & 2.87 & 10.03 & 0.48 & 0.16 & -2.94 & -0.75 & 0.139 \\
$\mathrm{~B}_{\mathrm{ML}}$ & 4.2 & 3.02 & 8.72 & 0.34 & 0.1 & -4.85 & -0.84 & 0.42 \\
$\mathrm{C}_{\mathrm{ML}}$ & 3.9 & 3.34 & 6.11 & 0.33 & 0.07 & -5.47 & -0.98 & 0.432 \\
\hline
\end{tabular}

less negative from $\mathrm{C}$ to $\mathrm{B}$, and again from $\mathrm{B}$ to $\mathrm{A}$ (see Table 1). ${ }^{1}$ The differing values of $\gamma_{\mathrm{NO}}$ represent the observed change in tilt of the IFF from more negative values near Iceland where IFF slopes steeper, to less negative values near the Faeroe Islands where the front slopes more gently.

The surface jet represents the component of the Faeroe branch that is fed by the Iceland-Faeroe Front, with transport given by $Q_{\mathrm{FB}}=\iint_{A_{\mathrm{NO}}} u(y, z) d A_{\mathrm{NO}}$ (the area $A_{\mathrm{NO}}$ represents the cross sectional area bounded meridionally by the contours where the surface jet is at least $10 \%$ of its maximum, and depths shallower than $z=z_{\theta}$ ). Parameter $Q_{\mathrm{FB}}$ is nearly constant for all the experiments (see Table 1).

The second set of simulations, denoted by $\left\{\mathrm{A}_{\mathrm{ML}}\right.$, $\left.\mathrm{B}_{\mathrm{ML}}, \mathrm{C}_{\mathrm{ML}}\right\}$ (Fig. 3), represents a variation of the above initial conditions where the warm upper frontal layer (with $T \geq \theta$ ) has vertical shear and lateral stratification typical of mixed layer fronts. To introduce a mixed layer front that exists on the warm side of the outcropping polar front, we add a lateral temperature gradient, on depths shallower that $z_{\theta}$, to the temperature distribution in experiments $\{\mathrm{A}, \mathrm{B}, \mathrm{C}\}$. Analytically the frontal structure is given by

$$
T(y, z)_{\mathrm{ML}}=T(y, z)-\Delta T_{\mathrm{ML}} \tanh \left(\frac{y-y_{\mathrm{ML}}}{L_{\mathrm{ML}}}\right) \mathscr{H}\left(z-z_{\theta}\right),
$$

where $T(y, z)$ is the temperature distribution that defines the experiments $\{\mathrm{A}, \mathrm{B}, \mathrm{C}\}$. Parameter $\Delta T_{\mathrm{ML}}$ represents half the temperature jump associated with the lateral temperature gradient that results in the mixed layer front before gravitational adjustment. Parameters $y_{\mathrm{ML}}, L_{\mathrm{ML}}$ represent a centering parameter for the mixed layer front and the deformation scale of the mixed layer

\footnotetext{
${ }^{1}$ The subscript "NO" indicates that $\gamma$ is averaged over a region where the near-bottom velocity is at least $75 \%$ of its maximum value, on the Nordic flank of the ridge.
}

front, respectively. Parameter $\mathscr{H}\left(z-z_{\theta}\right)$ represents the Heaviside function applied at a varying depth level $z_{\theta}$. The frontal temperature distribution, as given by (3), represents an outcropping polar front with a lateral temperature gradient and vanishing vertical stratification above and near the outcropping thermocline that results from convective homogenization of the upper mixed layer, thus representing winter conditions.

The important parameters that control the structure of the mixed layer front in experiments $\left\{\mathrm{A}_{\mathrm{ML}}, \mathrm{B}_{\mathrm{ML}}, \mathrm{C}_{\mathrm{ML}}\right\}$ are the mixed layer Richardson number $\mathrm{Ri}_{\mathrm{ML}} \sim O(1)$, the mixed layer deformation radius $\mathrm{Rd}_{\mathrm{ML}}=N_{\mathrm{ML}} H_{\mathrm{ML}} / f$, with $H_{\mathrm{ML}}$ being the depth of the mixed layer, and the mixed layer Burger number $\mathrm{Bu}_{\mathrm{ML}} \ll 1$ (see Table 2). The (theoretical) growth rate and wavelength for the most unstable wave, given $\mathrm{Ri}_{\mathrm{ML}} \approx 1.9$ using (1) and (2) for the three simulations $\left\{\mathrm{A}_{\mathrm{ML}}, \mathrm{B}_{\mathrm{ML}}, \mathrm{C}_{\mathrm{ML}}\right\}$, is $\sigma^{-1} \approx 0.5$ days and $\lambda \approx 5 \mathrm{~km}$. The mixed layer frontal region is located on the anticyclonic flank of the jet, within a background barotropic anticyclonic shear that introduces a strong barotropic flow within the mixed layer front $U_{\mathrm{bt}}$, such that the ratio $U_{\mathrm{bc}_{\mathrm{ML}}} / U_{\mathrm{bt}_{\mathrm{ML}}} \ll 1$.

As in experiments $\{\mathrm{A}, \mathrm{B}, \mathrm{C}\}$, we vary the location of the jet with respect to the ridge crest, thus varying the slope parameter $\gamma_{\mathrm{NO}}$, but the mixed layer parameters that are set by a local adjustment of purely vertical isotherms experience little modification between experiments. Thus, the first set of experiments $\{\mathrm{A}, \mathrm{B}, \mathrm{C}\}$ can be thought of control cases for $\left\{\mathrm{A}_{\mathrm{ML}}, \mathrm{B}_{\mathrm{ML}}, \mathrm{C}_{\mathrm{ML}}\right\}$, respectively, and the presence of the mixed layer frontal region, characterized by $\mathrm{Ri}_{\mathrm{ML}} \sim O(1)$ within the Atlantic side of the main front (warm temperature classes $T \geq \theta$ ), allows us to consider experiments $\left\{\mathrm{A}_{\mathrm{ML}}, \mathrm{B}_{\mathrm{ML}}, \mathrm{C}_{\mathrm{ML}}\right\}$ as representing wintertime conditions, and therefore allows us to test whether topography and mesoscale instability can have an effect on mixed layer instability.

For all the simulations we use quadratic bottom drag, with drag coefficient $C_{D}=2.5 \times 10^{-3}$. The bottom flow below the main thermocline $\theta$ is westward, resulting in upwelling conditions within a thin bottom Ekman layer on the Nordic flank of the ridge and downwelling conditions 
TABLE 2. Relevant parameters for the mixed layer front, averaged over the width of mixed layer front.

\begin{tabular}{ccccccccc}
\hline \hline Experiment & $N_{\mathrm{ML}}^{2}\left(10^{-7}\right)$ & $S_{\mathrm{ML}}^{2}\left(10^{-8}\right)$ & $H_{T}$ & $H_{\mathrm{ML}}(\mathrm{m})$ & $U_{\mathrm{bt}_{\mathrm{ML}}}\left(\mathrm{m} \mathrm{s}^{-1}\right)$ & $U_{\mathrm{bc}_{\mathrm{ML}}}\left(\mathrm{m} \mathrm{s}^{-1}\right)$ & $\mathrm{Ri}_{\mathrm{ML}}$ & $\mathrm{Rd}_{\mathrm{ML}}\left(\mathrm{km}^{-1}\right)$ \\
\hline $\mathrm{A}_{\mathrm{ML}}$ & 3.28 & 5.35 & 561 & 135 & 0.23 & 0.06 & 1.79 & 2.72 \\
$\mathrm{~B}_{\mathrm{ML}}$ & 3.81 & 5.48 & 685.6 & 125.4 & 0.23 & 0.05 & 1.98 & 2.73 \\
$\mathrm{C}_{\mathrm{ML}}$ & 3.51 & 5.52 & 823.3 & 102.5 & 0.25 & 0.05 & 1.8 & 2.47 \\
\hline
\end{tabular}

on the Atlantic flank (see Fig. 3). This represents a crude approximation to cross-ridge bottom overflow. The bottomintensified gravity current on the Atlantic flank is in thermal wind balance with the gently sloping frontal isotherms that connect to the surface outcrop. The ratio $\gamma_{\mathrm{NA}}(\gamma$ is averaged in a region where the bottom flow is at least $75 \%$ of its maximum in absolute value, south of the ridge crest) is close to unity for all the experiments, in agreement with observations of the region (Beaird et al. 2013). As a result, the bottom-intensified gravity current is more stable to baroclinic instability than that of the upper ocean front and does not play a role in this study, while frictional effects on the bottom current are still at work. The zonal volume flux by the bottom-intensified flow $Q_{\mathrm{OV}}=\iint_{A_{\mathrm{NA}}} \bar{u} d A_{\mathrm{NA}}$ (the area $A_{\mathrm{NA}}$ represents the cross sectional area bounded meridionally by the contours where the surface jet is at least $75 \%$ of its maximum in absolute value, and depths greater than $z=z_{\theta}$ ) is a measure of the strength of the nonlocal overflow transport associated with the Faeroe Bank channel (Prater and Rossby 2005; Beaird et al. 2013), and is always negative representing westward transport (see Table 1).

The IFR is not an infinitely long ridge and the IFF is not reentrant, but it is also not (statistically) equilibrated. The warm water inflow across the IFR has a finite time residence that can be approximated by the advective time scale of the front $T_{\mathrm{Adv}}=u_{\text {max }_{\mathrm{NO}}} / L_{x} \approx 10$ days (for all simulations). As such, the IFF can be thought of as always in the initial stages of (mesoscale) baroclinic instability. Here, we focus on the instability behavior up until a time $T_{\text {Adv }}$ after the initial development of baroclinic instability.

\section{Model results}

In this section, we examine the characteristics of the initial development of the instability and the impact of the eddies on the mean flow once they reach finite amplitude. We begin by looking at the differences of the instability growth rates in the different experiments, before performing an energetics analysis that allows us to identify the dominant mechanisms driving the instability. We end this section by looking at the effects of eddies on the cross-slope transport, where we examine the modification of the bottom Ekman transport and also the eddy-driven overturning circulation that is localized to the instability. To distinguish between mean and eddy components of the flow, we define the mean as the zonal average $\overline{(\cdot)}=\left(1 / L_{x}\right) \int_{0}^{L_{x}}(\cdot) d x$ and the eddy as any deviation from the mean (e.g., given the mean flow $\overline{\mathbf{u}}$, the eddy component is $\mathbf{u}^{\prime}=\mathbf{u}-\overline{\mathbf{u}}$ such that $\overline{\mathbf{u}^{\prime}} \equiv 0$, at any given time).

\section{a. Baroclinic instability: Initial development}

The initial development of the unstable jet is controlled by the growth of the most unstable wave, which in all simulations takes place at the surface. In experiments $\{\mathrm{A}, \mathrm{B}, \mathrm{C}\}$, the eddies are more pronounced at the location of the frontal surface outcrop, with their behavior associated with their location relative to that of the surface frontal jet, even at the nonlinear finite amplitude phases (Figs. 4a,c,e). Eddies in experiments $\left\{A_{M L}, B_{M L}, C_{M L}\right\}$, on the other hand, grow south of the location of the surface jet within the mixed layer front and although these eddies break northward toward the location of the surface jet once reaching finite amplitude (Figs. 4b,d,f), the controlling dynamics during initial growth are associated with the baroclinicity within the mixed layer.

The initial development of the instability when it is dominated by a single most unstable mode can be analyzed by examining the time evolution of the volumeintegrated eddy kinetic energy $E_{\mathrm{EKE}}=(1 / 2) \overline{\mathbf{u}_{h}^{\prime 2}}$, where $\mathbf{u}_{h}^{\prime}$ represents the horizontal component of the eddy velocity. Assuming that the initial perturbation growth is exponential [so that $E_{\mathrm{EKE}}(t) \sim E_{\mathrm{EKE}}(0) \exp (2 \sigma t)$ ], the growth rate $\sigma$ of the perturbation kinetic energy can be estimated, following Badger and Hoskins (2001) and Reszka et al. (2002), by

$$
\sigma=\frac{1}{2} \frac{d}{d t}\left\{\ln \left[\frac{E_{\mathrm{EKE}}(t)}{E_{\mathrm{EKE}}(0)}\right]\right\} .
$$

All of the model experiments show a constant growth rate (Fig. 5) with the most unstable mode $\left[\sigma(t) \sim \sigma_{0}\right]$ dominating only for a finite time $T_{\sigma}$. For experiments $\{\mathrm{A}, \mathrm{B}, \mathrm{C}\}$, the initial growth rate decreases as the initial frontal jet moves into deeper water $(42 \%$ reduction from $\mathrm{A}$ to $\mathrm{B}$, and a reduction of $36 \%$ from $\mathrm{B}$ to $\mathrm{C}$; Fig. 5a). The calculated growth rates imply a growth time scale $\tau=(2 \sigma)^{-1} \approx 1$ day in experiment $A, \tau=$ 2.5 days in $\mathrm{B}$, and about $\tau=4$ days in experiment $\mathrm{C}$. The length scale of the instability $\lambda \approx 60 \mathrm{~km}$ is the same for 

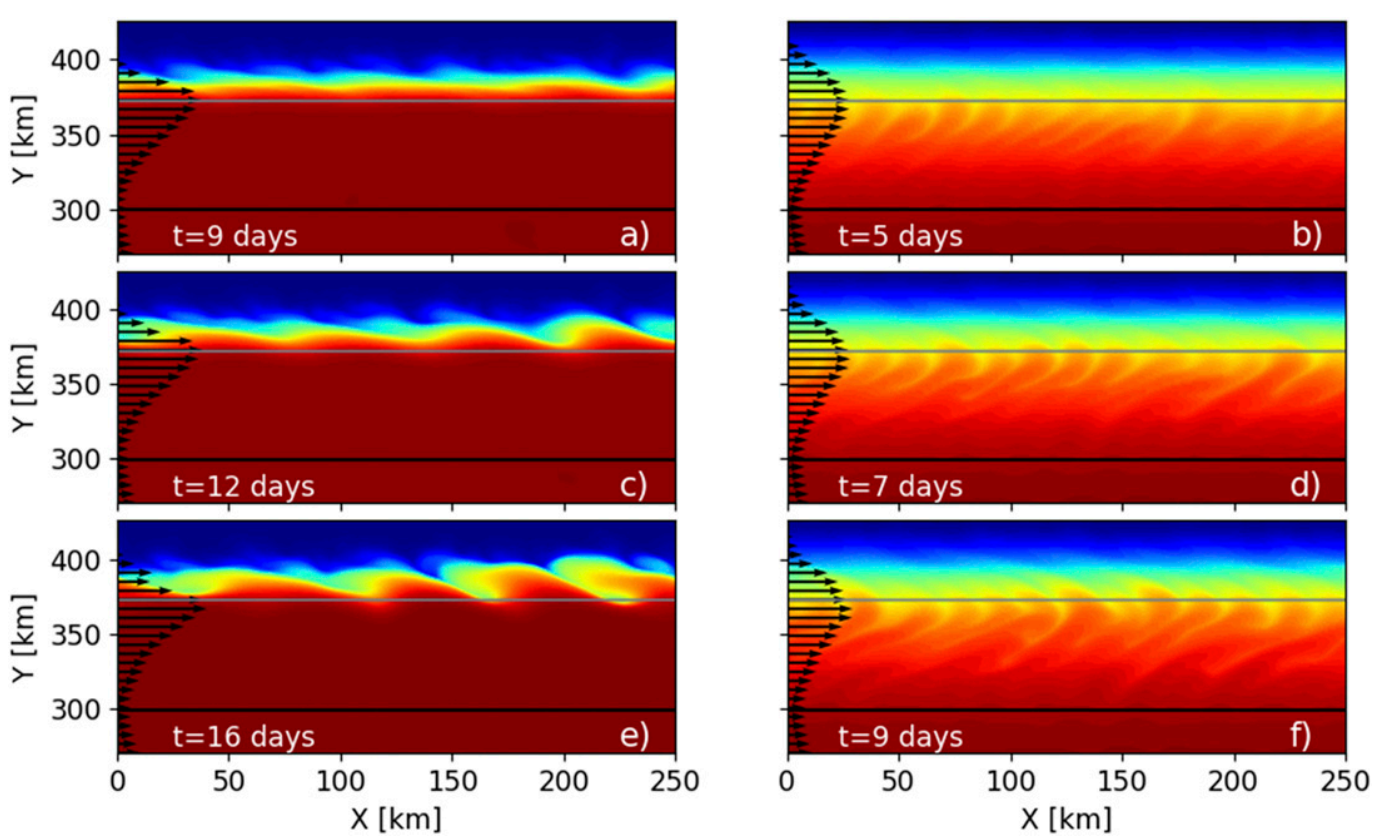

FIG. 4. Sea surface temperature showing the development of baroclinic instability in (left) experiment B and (right) experiment $\mathrm{B}_{\mathrm{ML}}$, the latter one characterized by the presence of mixed layer eddies. Here, $\Delta T=6^{\circ} \mathrm{C}$ across the front. The black arrows represent the zonal-mean surface jet $\bar{u}(y, 0, t)$, with the gray line showing the location of surface jet maximum $\max [\bar{u}(y)]$ before the onset of instability. The ridge crest is identified by the solid black line.

experiments $\{\mathrm{A}, \mathrm{B}, \mathrm{C}\}$. The observed reduction in growth rates (increase growth time scale) agrees well with the expected behavior as a result of the frontal jet moving to a region with a more stabilizing slope parameter $\gamma_{\mathrm{NO}}$, that is, $\gamma_{\mathrm{NO}}$ becomes more negative. In addition, the bottom-layer thickness $h_{2}=\int_{z=-h}^{z=z_{\theta}} d z$ increases with respect to the upper-layer thickness $h_{1}=\int_{z=z_{\theta}}^{z=\eta} d z$ as the initial jet moves toward deeper water (from A to B, and then from B to C), thus increasing the depth ratio parameter and therefore indicating a
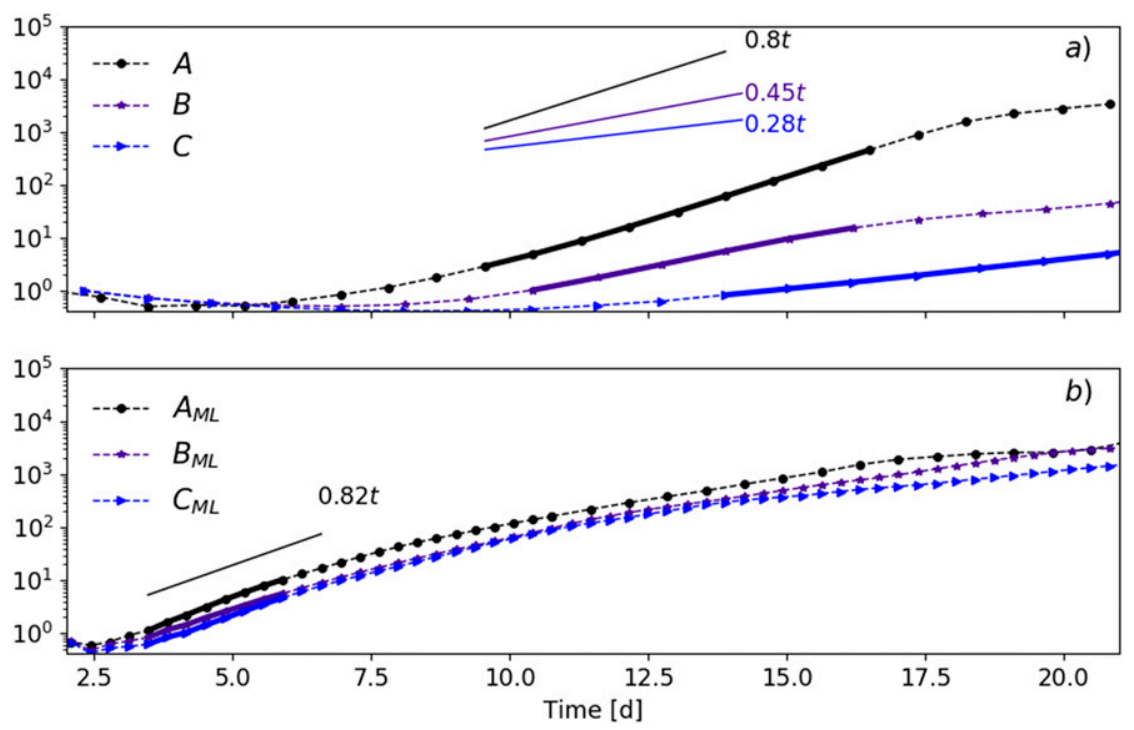

FIG. 5. Normalized Eddy kinetic energy $\left[E_{\mathrm{EKE}}(t) / E_{\mathrm{EKE}}(0)\right]$ for (a) $\{\mathrm{A}, \mathrm{B}, \mathrm{C}\}$ and (b) $\left\{\mathrm{A}_{\mathrm{ML}}, \mathrm{B}_{\mathrm{ML}}, \mathrm{C}_{\mathrm{ML}}\right\}$ as a function of time. Thick, short, colored lines represent the linear approximation to the most unstable growth $\sigma(t)=\sigma_{0}$. The value of $\sigma_{0}$ is calculated by fitting an exponential curve of the form $a e^{b t}$ to each normalized kinetic energy. Then, $2 \sigma_{0}=b$. 


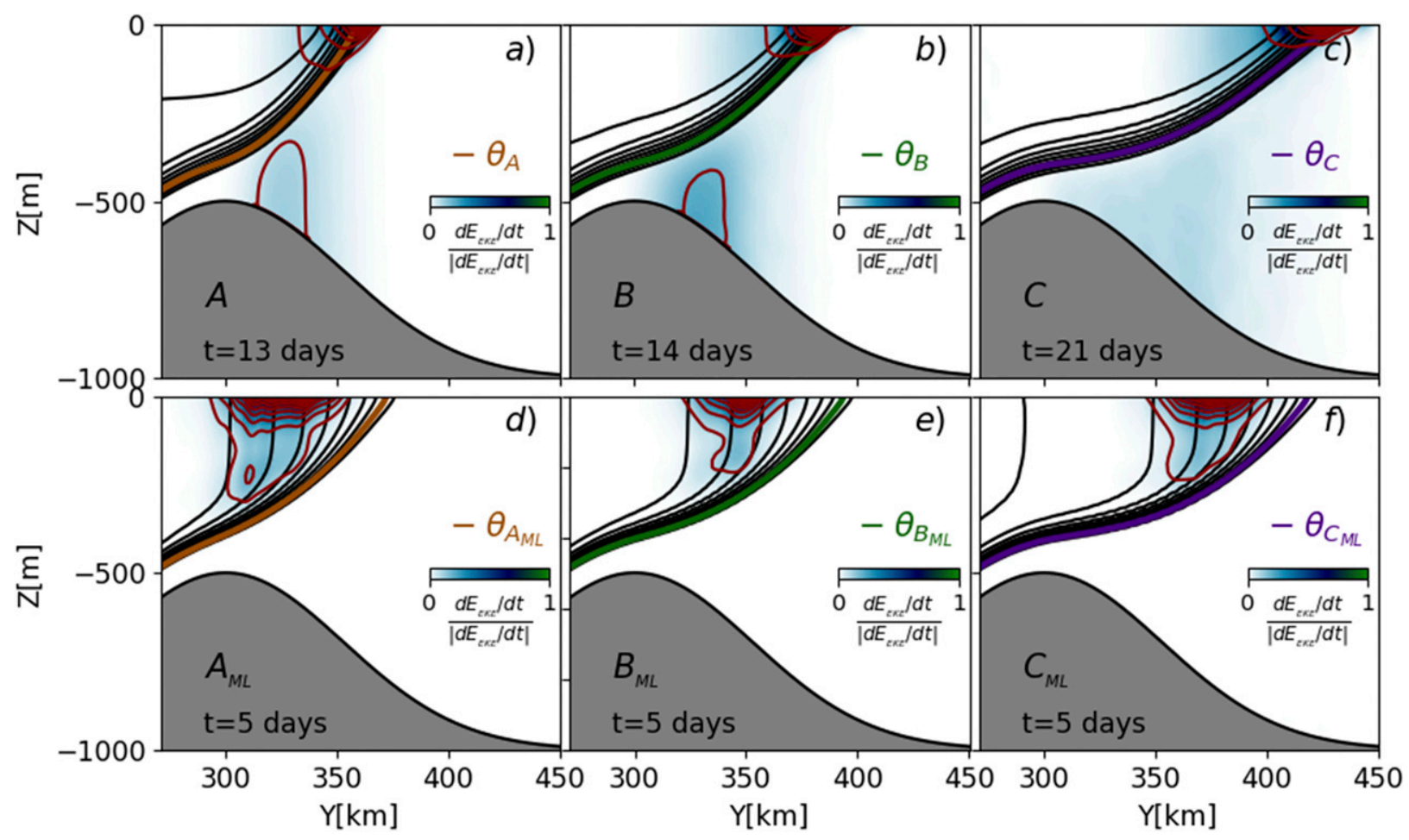

FIG. 6. Spatial distribution of normalized $d E_{\mathrm{EKE}} / d t$ for all simulations when the growth is approximately linear $\left(\sigma \approx \sigma_{0}\right)$. Red contours represent the location of normalized $E_{\mathrm{EKE}}$ with $10 \%$ increments, and black contours represent mean temperature $\bar{T}$, with $0.5^{\circ} \mathrm{C}$ increments. Thick colored contours indicate the location of the thermocline $\theta$.

theoretical reduction in the growth rate (from A to B and then to C). Thus, both the changes in slope parameter and changes in depth ratio act together to reduce the growth rate as the jet is shifted toward greater (total) depth.

The growth rates of experiments $\left\{\mathrm{A}_{\mathrm{ML}}, \mathrm{B}_{\mathrm{ML}}, \mathrm{C}_{\mathrm{ML}}\right\}$ show little modification as the jet moves toward deeper waters (Fig. 5b). The growth rate decreases $5 \%$ from $A_{M L}$ to $B_{M L}$ even when the location of maximum $E_{\mathrm{EKE}}$ shifts toward deeper waters, as seen by examining the relative meridional location of maximum $d E_{\mathrm{EKE}} / d t$ and maximum $E_{\mathrm{EKE}}$, between experiments (see Figs. 6d-f). The calculated growth rates imply an $e$-folding (growth) time scale for $E_{\mathrm{EKE}}$ of $\tau=(2 \sigma)^{-1} \approx 1$ day. In addition, the maximum in $d E_{\mathrm{EKE}} / d t$ and the maximum in the surface jet do not coincide, suggesting that the MLEs grow separately from the mesoscale instability of the mean jet, despite the mean jet being unstable. The calculated growth rate for baroclinic instability in $\mathrm{C}_{\mathrm{ML}}$, however, is almost the same as that of $\mathrm{A}_{\mathrm{ML}}$. This agrees well with the Richardson number $\left(\mathrm{Ri}_{\mathrm{ML}}\right)$ calculated at the location of maximum $d E_{\mathrm{EKE}} / d t$ during initial linear growth (see Table 2) and reflects no direct influence of the changes in bottom depth.
MLEs have a lateral scale $\lambda \approx 10 \mathrm{~km}$ around day 7 , after the onset of initial instability, a much smaller scale than the width of the mixed layer frontal region $L_{\mathrm{ML}}$ (Fig. 4b). This results in eddies having different sizes and growth rates depending on where they originate with their properties depending on the local slope of the base of the mixed layer and local barotropic shear. Nevertheless, the growth rate represents that of the most unstable modes for each simulation, and these modes largely determine the evolution of the mixed layer front. During their initial development, MLEs are entirely confined to the upper warm waters (corresponding to the temperature classes warmer than $\theta$ ), with a strong vertical density jump associated with the thermocline $\theta$ acting as the bottom boundary to the surface mixed layer baroclinic instability in the initial development phase, making growing MLEs insensitive to the topographic slope (Boccaletti et al. 2007).

\section{b. Eddy-mean energetics}

To better understand the differences between the two sets of experiments and to help identify the dominant mechanisms driving the instabilities, we examine the time evolution of the mean and eddy kinetic energy. The mean and eddy kinetic energy equations are 
obtained by projecting the horizontal mean $\overline{\mathbf{u}}_{h}=(\bar{u}, \bar{v})$ and horizontal eddy $\mathbf{u}_{h}^{\prime}=\left(u^{\prime}, v^{\prime}\right)$ velocity vectors onto the horizontal momentum equations and subsequently performing the zonal average. The equations governing the mean and eddy kinetic energy, ignoring cubic terms in the perturbation that result from the triple multiplication of eddy variables (negligible only during initial, small-amplitude eddy development), are

$$
\begin{aligned}
& \frac{\partial E_{\mathrm{MKE}}}{\partial t}+\nabla^{x} \cdot\left[\overline{\mathbf{u}}\left(E_{\mathrm{MKE}}+\bar{p}\right)\right]=\underbrace{\left(\overline{u^{\prime} v^{\prime}} \partial_{y} \bar{u}+\overline{v^{\prime} v^{\prime}} \partial_{y} \bar{v}\right)}_{C_{h}}+\underbrace{\left(\overline{u^{\prime} w^{\prime}} \partial_{z} \bar{u}+\overline{v^{\prime} w^{\prime}} \partial_{z} \bar{v}\right)}_{C_{v}}+\underbrace{\bar{w} \bar{b}}_{C_{\mathrm{MA}}}+\underbrace{\overline{\mathbf{u}} \cdot \overline{\mathscr{D}}}_{\bar{\varepsilon}}+O\left(\overline{\mathbf{u}}^{3}\right), \\
& \frac{\partial E_{\mathrm{EKE}}}{\partial t}+\nabla^{x} \cdot\left(\overline{\mathbf{u}} E_{\mathrm{EKE}}+\overline{\mathbf{u}^{\prime} p^{\prime}}\right)=-\underbrace{\left(\overline{u^{\prime} v^{\prime}} \partial_{y} \bar{u}+\overline{v^{\prime} v^{\prime}} \partial_{y} \bar{v}\right)}_{C_{h}}-\underbrace{\left(\overline{u^{\prime} w^{\prime}} \partial_{z} \bar{u}+\overline{v^{\prime} v^{\prime}} \partial_{z} \bar{v}\right)}_{C_{v}}+\underbrace{\overline{\mathbf{u}^{\prime} \cdot \mathscr{D}}}_{C_{\mathrm{EA}} \overline{w^{\prime} b^{\prime}}}+\underbrace{\overline{\mathbf{u}^{\prime}}}_{\bar{\varepsilon}^{\prime}} \overline{O\left(\overline{\mathbf{u}^{\prime 3}}\right),}
\end{aligned}
$$

where $\nabla^{x}=\left(0, \partial_{y}, \partial_{z}\right)$. The second terms on the lhs of both (5) and (6) represent adiabatic redistribution of kinetic energy by advective convergence and by pressure work, and therefore do not represent net sources or sinks of energy (i.e., their integral are zero) (Heifetz et al. 1998). The dissipation terms of the mean kinetic energy $E_{\mathrm{MKE}}$ and eddy kinetic energy $E_{\mathrm{EKE}}$ are given by $\bar{\varepsilon}$ and $\varepsilon^{\prime}$, respectively, and constitute an irreversible loss of total kinetic energy that result from viscous (harmonic) numerical dissipation. The four terms $C_{h}, C_{v}, C_{\mathrm{EA}}$, and $C_{\mathrm{MA}}$ represent energy convergence that promotes energy transfer associated with the presence of instability processes. Both $C_{h}$ and $C_{v}$ represent flow of energy between the mean and eddy kinetic energy and require the presence of mean horizontal $C_{h}$ or mean vertical $C_{v}$ shear, and result from a mechanism of barotropic or Kelvin-Helmholtz instability (Samelson and Chapman 1995). Parameter $C_{\mathrm{MA}}$ represents the energy transfer between $E_{\mathrm{MKE}}$ and the mean available potential energy $E_{\mathrm{MAPE}}$, while $C_{\mathrm{EA}}$ represents the transfer of energy between $E_{\mathrm{EKE}}$ and the eddy available potential energy $E_{\mathrm{EAPE}}$.

The evolution of the mean and eddy kinetic energy budgets in (5) and (6) demonstrates the processes that control both the linear and nonlinear phases of the instability (Fig. 7). Here, we analyze the $E_{\mathrm{EKE}}$ budgets for $\mathrm{C}$ and $\mathrm{C}_{\mathrm{ML}}$, which represent the typical initial behaviors of $\{\mathrm{A}, \mathrm{B}, \mathrm{C}\}$ and $\left\{\mathrm{A}_{\mathrm{ML}}, \mathrm{B}_{\mathrm{ML}}, \mathrm{C}_{\mathrm{ML}}\right\}$, respectively. In experiment $\mathrm{C}$, baroclinic production of $E_{\mathrm{EKE}}\left(C_{\mathrm{EA}}\right)$ dominates the initial growth $(t=16-21$ days $)$, indicating that baroclinic instability is the dominant mechanism that feeds the growing eddy field (Fig. 7c). Baroclinic production is positive throughout, signaling a continuous transfer energy from eddy available potential energy $E_{\text {EAPE }}$ into $E_{\text {EKE }}$. During this initial growth both $C_{h}$ and $C_{v}$ are nonzero and negative but much smaller and therefore nondominant. After the initial growth phase in experiment $\mathrm{C}\left(t>21\right.$ days after initialization), $C_{h}$ dominates the evolution of $E_{\mathrm{EKE}}$, driving a decrease in $E_{\mathrm{EKE}}$ and an increase in $E_{\mathrm{MKE}}$. This coincides with wave breaking and the eventual separation of cold-core eddies that propagate southward toward shallow water observed (but not analyzed here), characteristic of the life cycle of fronts (Simmons and Hoskins 1978; Samelson and Chapman 1995; Skyllingstad and Samelson 2012).

The evolution of $E_{\mathrm{EKE}}$ for simulations $\mathrm{A}_{\mathrm{ML}}$ and $\mathrm{B}_{\mathrm{ML}}$ is very similar to that of $\mathrm{C}_{\mathrm{ML}}$ (shown in Fig. 7d). Eddy energy growth is dominated throughout by baroclinic production term $C_{\mathrm{EA}}$, with very small net contributions to $E_{\mathrm{EKE}}$ by $C_{h}$. Harmonic viscous dissipation promotes a small but continuous sink on the energy balance.

The growth in $E_{\mathrm{EKE}}$ is greatest near the upper and bottom boundaries that vertically bound the growing baroclinic waves, in agreement with the energetics within the Eady model (Eady 1949; Heifetz et al. 1998), which for $\{\mathrm{A}, \mathrm{B}, \mathrm{C}\}$ these boundaries are the ocean surface and bottom topography (Fig. 6). Thus, for $\{\mathrm{A}, \mathrm{B}, \mathrm{C}\}$ the instability is full depth. The growth in $E_{\mathrm{EKE}}$ is greatest within the mixed layer front for experiments $\left\{\mathrm{A}_{\mathrm{ML}}, \mathrm{B}_{\mathrm{ML}}, \mathrm{C}_{\mathrm{ML}}\right\}$, bounded above by the ocean surface and below by the thermocline $\theta$. This implies that surface-intensified modes grow by extracting perturbation available potential energy and restratifying the mixed layer front (Boccaletti et al. 2007).

The difference of the vertical structure of the instability waves between $\{\mathrm{A}, \mathrm{B}, \mathrm{C}\}$ and $\left\{\mathrm{A}_{\mathrm{ML}}, \mathrm{B}_{\mathrm{ML}}, \mathrm{C}_{\mathrm{ML}}\right\}$ is even more apparent in the distribution of the dominant terms in the eddy kinetic energy budgets (6) in temperature space. During linear baroclinic instability (e.g., the Eady problem), buoyancy production $C_{\mathrm{EA}}$ is greatest where $d E_{\mathrm{EKE}} / d t$ is minimum, which for experiments $\{\mathrm{A}, \mathrm{B}, \mathrm{C}\}$ is near the thermocline $\theta$ (Figs. $8 \mathrm{a}-\mathrm{c}$ ), since it is there that the greatest temperature perturbations take place. In experiments $\left\{\mathrm{A}_{\mathrm{ML}}, \mathrm{B}_{\mathrm{ML}}, \mathrm{C}_{\mathrm{ML}}\right\}$, the spatial distribution of both $d E_{\mathrm{EKE}} / d t$ and $C_{\mathrm{EA}}$ is entirely located in the upper 

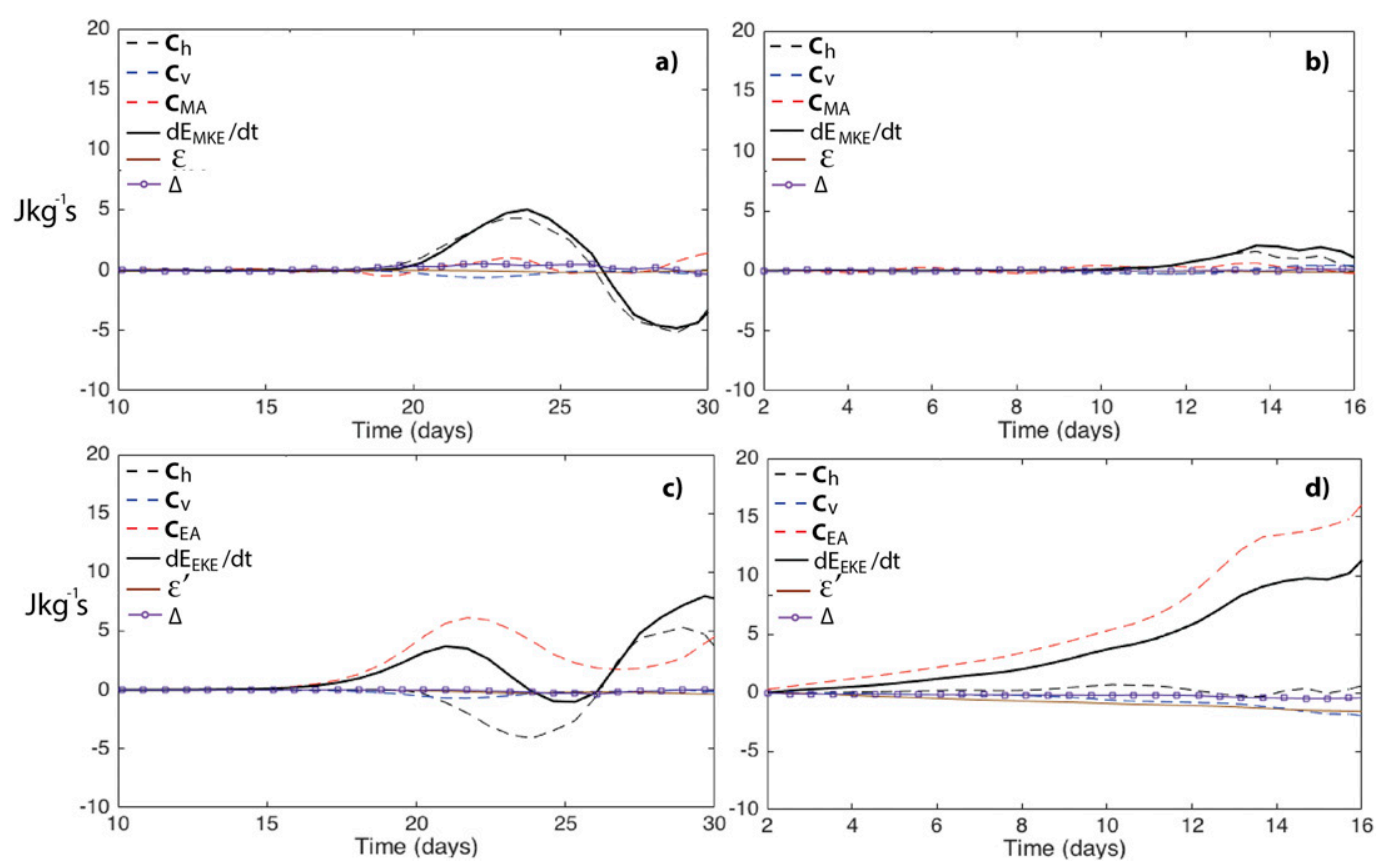

FIG. 7. Terms in the (top) $E_{\mathrm{MKE}}$ and (bottom) $E_{\mathrm{EKE}}$ budget equations for experiments (a),(c) C and (b),(d) $\mathrm{C}_{\mathrm{ML}}$. Parameters $\varepsilon$ and $\varepsilon^{\prime}$ were calculated by multiplying $\overline{\mathbf{u}_{h}}$ and $\mathbf{u}_{h}^{\prime}$ times the horizontal viscosity terms that are calculated within the model diagnostics. The $\Delta$ represents the residual from the budgets in (5) and (6).

warm layer $(\bar{T}>\theta)$, and decays exponentially to zero below the thermocline $\theta$. This means that the mechanism for instability is confined above the thermocline, which acts as a bottom PV sheet that drives the instability process (Callies et al. 2016). Furthermore, the confinement above the thermocline of the mixed layer baroclinic instability suggest that during initial development, bottom topography has no influence on the initial growth of mixed layer eddies, a result that agrees with the calculated growth rates.

The sloping bottom topography below the thermocline on the Nordic flank, however, destabilizes the flow at the mesoscales during the initial growth and can still have an effect on the instability in $\left\{\mathrm{A}_{\mathrm{ML}}, \mathrm{B}_{\mathrm{ML}}, \mathrm{C}_{\mathrm{ML}}\right.$ \} after the initial growth. Just as the configuration in experiment $\mathrm{A}$ is more unstable to that of $\mathrm{B}$ and $\mathrm{C}$ owing to sloping bottom topography, the same is true for $A_{M L}$ with respect to $B_{M L}$ and $C_{M L}$, even though this is not seen during initial growth. Eight days after initial development (12 days after model initialization), the spatial structure of $d E_{\mathrm{EKE}} / d t$ associated with $\mathrm{A}_{\mathrm{ML}}$ shows evidence that the instability fills the water column (Fig. 9d). At the bottom $d E_{\mathrm{EKE}} / d t$ shows a secondary maximum. The spatial distribution of $d E_{\mathrm{EKE}} / d t$ with respect to the mean temperatures also shows the full depth growing instability, since it no longer decays to zero below the thermocline at this time
(Fig. 10d). This shows that, while sloping bottom topography does not affect the initial growth rates of mixed layer eddies, we find that it allows a faster growth of mesoscale modes whenever the sloping bottom acts to destabilize the bottom layer in agreement with mesoscale results (Blumsack and Gierasch 1972; Lozier and Reed 2005; Isachsen 2011). In experiments $\left\{\mathrm{A}_{\mathrm{ML}}, \mathrm{B}_{\mathrm{ML}}, \mathrm{C}_{\mathrm{ML}}\right\}$, the spatial distribution of eddy kinetic energy growth and buoyancy production shows various maxima over a range of temperature classes, a direct consequence of the MLEs being much smaller than the lateral extent of the mixed layer frontal region (Figs. 10d-f and Figs. 11-f, respectively). In contrast, the spatial distribution of eddy kinetic energy growth and buoyancy production of the instability in experiments $\{\mathrm{A}, \mathrm{B}, \mathrm{C}\}$ shows a maximum, most likely associated with the most unstable growing mode that is dominating the eddy variability (Figs. 11a-c, respectively).

The continuous large contribution of the buoyancy production on the evolution of $E_{\mathrm{EKE}}$ represents continuous restratification and lateral heat advection that extends over most of the time period considered in this analysis. The restratification is characterized by a net change in the zonally averaged potential energy of the system that results from the cross-slope adiabatic heat flux, which we investigate next. 

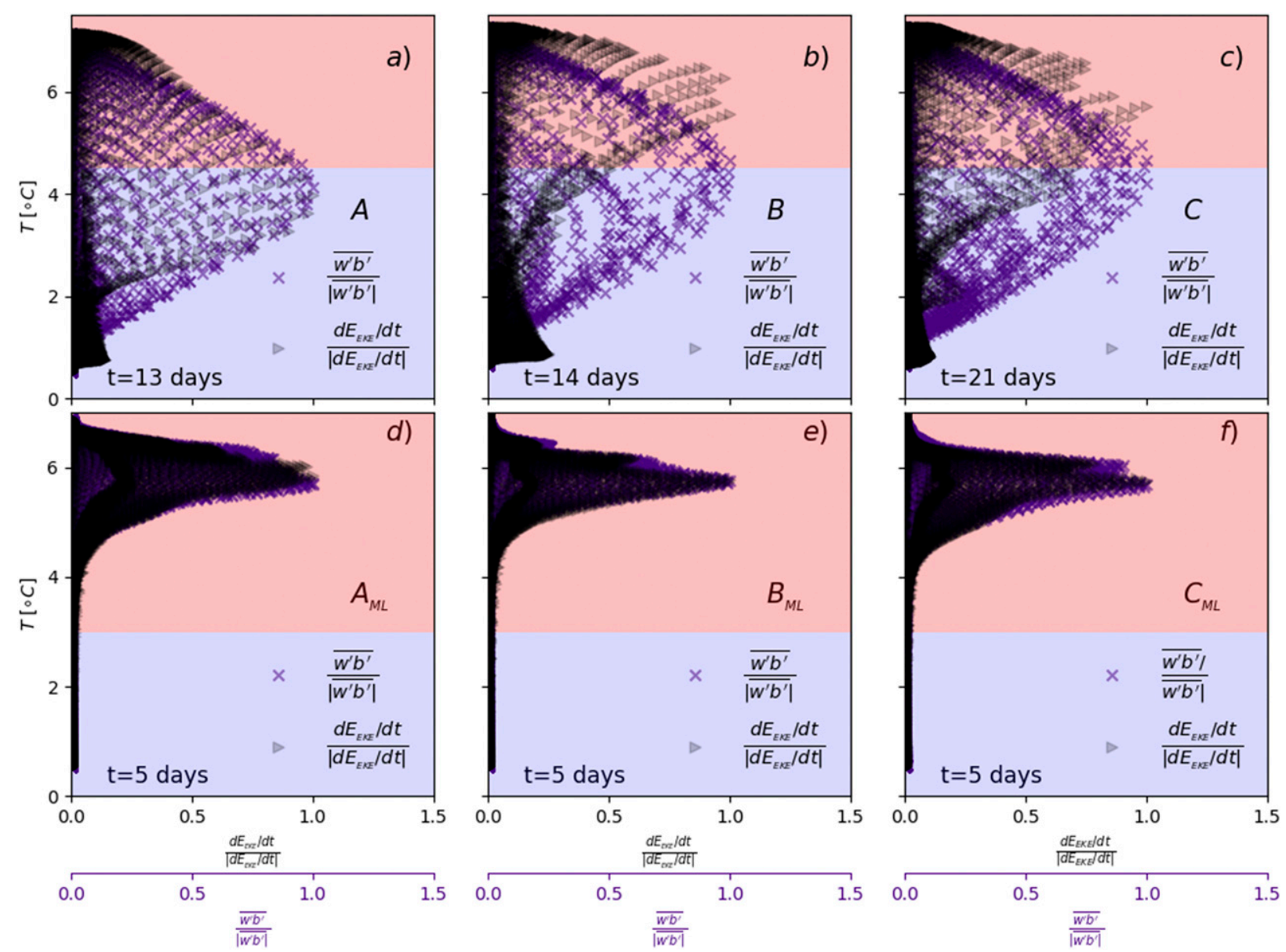

FIG. 8. Distribution in (mean) temperature space of normalized eddy kinetic growth $d E_{\mathrm{EKE}} / d t$ and normalized buoyancy production $C_{\mathrm{EA}}=\overline{w^{\prime} b^{\prime}}$ during linear growth, corresponding to the spatial distribution shown in Fig. 6 . Red shading represents mean temperature greater than that of the thermocline $z=\theta(y, z)$ (and thus the upper layer), and blue shading represent mean temperature values lower than that of the mean thermocline (lower layer).

\section{c. Cross-slope transport}

In this section we look at the meridional transport driven by the eddies and the mean flow. The (along isobath) mean flow promotes a cross-slope transport in the presence of bottom friction (bottom arrows in Fig. 3), where most of the transport is confined within a narrow bottom Ekman layer of thickness $\delta_{\mathrm{Ek}}=\sqrt{2 \nu_{v} / f} \approx 7 \mathrm{~m}$, where $\nu_{v}$ is the vertical viscosity. The mean flow configuration favors, through bottom Ekman transport $V_{\mathrm{Ek}}$, downwelling conditions on the Atlantic flank of the ridge and upwelling conditions on the Nordic flank of the ridge (MacCready 1994; Condie 1995; Wåhlin and Walin 2001; Brink and Lentz 2010). The term $V_{\mathrm{Ek}}$ corresponds to the southward component of the mean overturning circulation (MOC) across the ridge. In the absence of atmospheric forcing, the northward component of the MOC is associated with the interior ageostrophic velocities that help maintain the flow in thermal wind balance. In all simulations, the spindown of the mean flow promotes a slow decrease of the magnitude of the Ekman transport $\left|V_{\mathrm{Ek}}\right|$ over time, in the absence of eddies or any other external forcing (Fig. 12a), with oscillations most likely due to the presence of internal waves. During the time span of the initial growth, $\left|V_{\mathrm{Ek}}\right|$ shows no clear modification at either the crest of the ridge, or at the location of the maximum bottom velocities at either flank of the crest, for all simulations. In experiments $\{\mathrm{A}, \mathrm{B}, \mathrm{C}\}$ the transport $\left|V_{\mathrm{Ek}}\right|$ increases (becomes more southward) after the initial growth when the flow becomes nonlinear and cold-core lenses form that propagate southward toward the ridge crest. These eddies can promote the increase of the bottom southward transport by locally increasing the tilt of the frontal thermocline so that the bottom flow becomes more westward and thus $V_{\mathrm{Ek}}$ becomes more negative and southward, resulting in advection of cold water up the slope on the Nordic side of the ridge. 


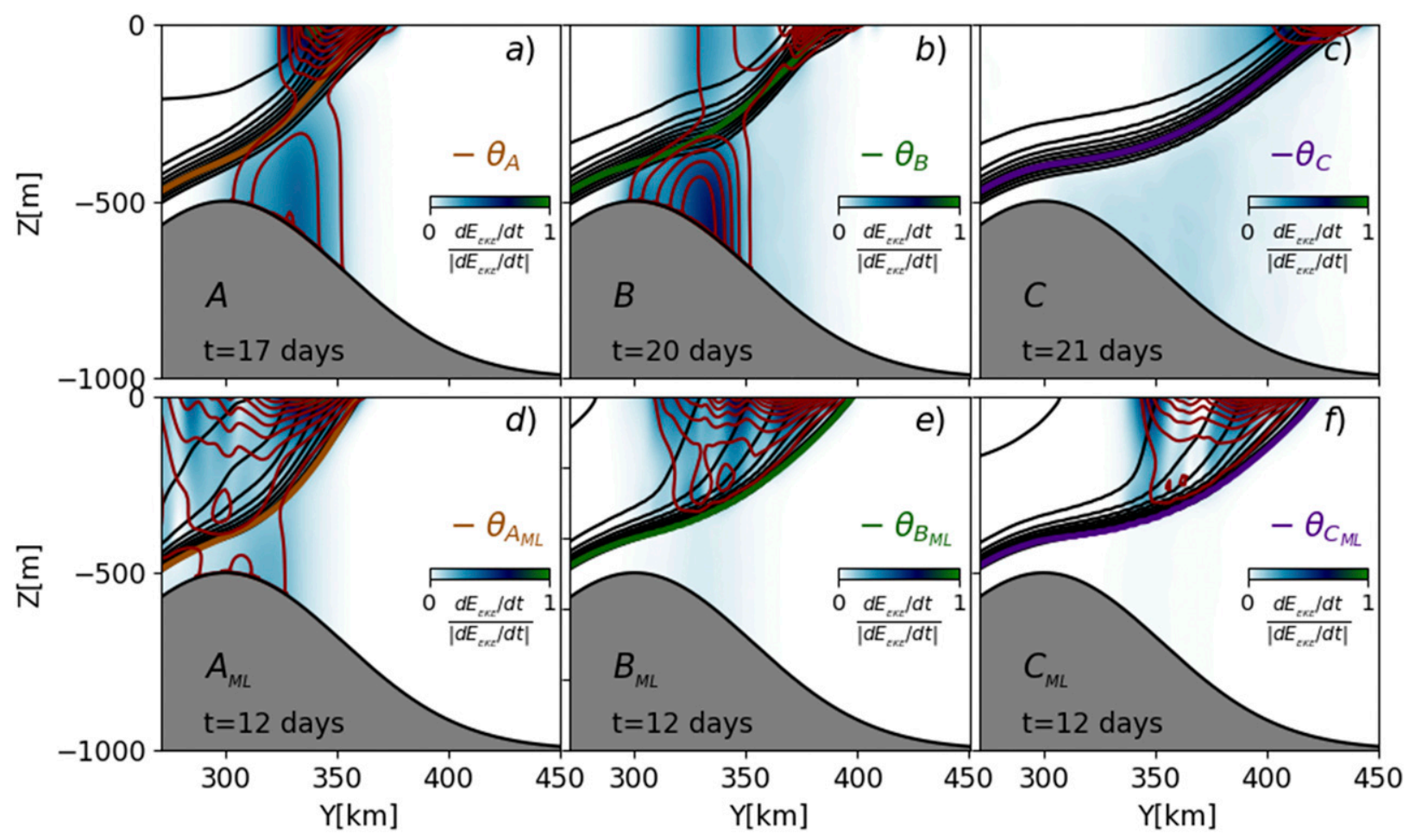

FIG. 9. Spatial distribution of normalized $d E_{\mathrm{EKE}} / d t$ for all simulations at a time much after the linear growth phase. Red contours represent the location of normalized $E_{\mathrm{EKE}}$ with $10 \%$ increments, and black contours represent mean temperature $\bar{T}$, with $0.5^{\circ} \mathrm{C}$ increments. Within each subfigure, the thick colored contour represents the location of the thermocline during linear development.

In experiments $\left\{\mathrm{A}_{\mathrm{ML}}, \mathrm{B}_{\mathrm{ML}}, \mathrm{C}_{\mathrm{ML}}\right\},\left|V_{\mathrm{Ek}}\right|$ shows no clear modification by the presence of MLEs over most of the timespan considered, that is, up to day 11 after initialization, long after the initial growth phase (Fig. 12b). Thus, the surface-confined MLEs have little to no influence on bottom flows throughout the initial growth and beyond. At around day 12, almost 9 days after the initial development and with the eddying flow field well developed, $\left|V_{\mathrm{Ek}}\right|$ shows a small decrease at the crest of the ridge (less southward transport), but most of the changes take place outside of the time span considered $\left(T_{\mathrm{Adv}}\right)$. In contrast to the eddies in experiments $\{\mathrm{A}, \mathrm{B}, \mathrm{C}\}$, the MLEs in experiments $\left\{\mathrm{A}_{\mathrm{ML}}, \mathrm{B}_{\mathrm{ML}}, \mathrm{C}_{\mathrm{ML}}\right\}$ are not horizontally isolated from each other, and instead eddies of different sizes fill the water column over the entire mixed layer front. Thus, the bottom transport may be dependent on the location of the bigger, most unstable eddies. The location of the $E_{\mathrm{EKE}}$ growth is maximum at the ridge crest for experiment $\mathrm{A}_{\mathrm{ML}}$, but shifts northward on $\mathrm{B}_{\mathrm{ML}}$ and $\mathrm{C}_{\mathrm{ML}}$. In experiments $\mathrm{B}_{\mathrm{ML}}$ and $\mathrm{C}_{\mathrm{ML}}, V_{\mathrm{Ek}}$ shows no clear change over the time scale considered, and thus, MLEinduced changes in $V_{\mathrm{Ek}}$ are very sensitive to the location of the maxima in $E_{\mathrm{EKE}}$ and $d E_{\mathrm{EKE}} / d t$.

Eddies promote an interior cross-front transport by the action of eddy fluxes along adiabatic surfaces (Vallis
2017). When the isothermal surfaces do not vary significantly with respect to the mean, the transformed Eulerian mean (TEM) developed for quasigeostrophic waves can be used to represent the circulation induced by the eddies (Plumb and Ferrari 2005; Stewart and Thompson 2015). The eddy-induced circulation $\psi^{*}$ in the primitive equations is given by

$$
\psi^{*}=\frac{\overline{v^{\prime} T^{\prime}} \bar{T}_{z}-\overline{w^{\prime} T^{\prime}} \bar{T}_{y}}{\left\|\nabla^{x} \bar{T}\right\|^{2}},
$$

where $\psi^{*}$ represents a circulation that, in the case of baroclinic instability waves, describes a clockwise relaxation of the tilting mean temperature surfaces $\bar{T}$ due to baroclinic eddy fluxes $\overline{v^{\prime} T^{\prime}}, \overline{w^{\prime} T^{\prime}}$. The experiments $\{\mathrm{A}, \mathrm{B}, \mathrm{C}\}$ are characterized by growth of baroclinic instability dominated by the most unstable mode, with its effects on the zonal mean represented by the residual overturning circulation. The residual circulation is strongest when eddies separate from the main frontal outcrop and propagate southward. As the eddies detach from the front southward toward the ridge crest, their effect on the front is to subduct waters along the main frontal thermocline (Figs. 13a-c). Here, the eddies do not propagate across the ridge crest during the time 

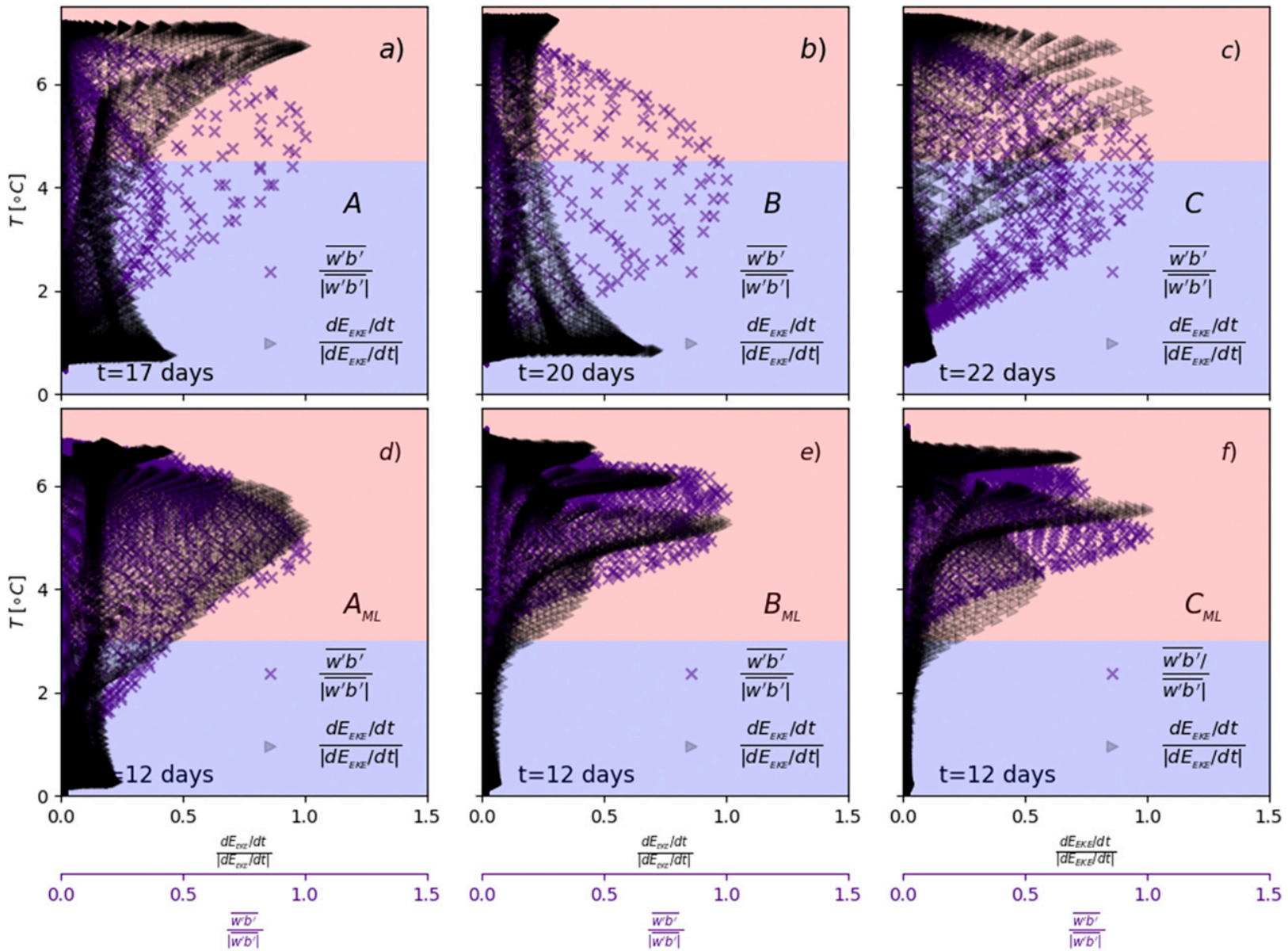

FIG. 10. Distribution in (mean) temperature space of normalized eddy kinetic growth $d E_{\mathrm{EKE}} / d t$ and normalized buoyancy production $C_{\mathrm{EA}}=\overline{w^{\prime} b^{\prime}}$ during linear growth, corresponding to the spatial distribution shown in Fig. 9. Red shading represents mean temperatures greater than that of the thermocline $z=\theta$ (and thus the upper layer), and blue shading represents mean temperature values lower than those of the thermocline (lower layer). The presence of many local maxima in $d E_{\mathrm{EKE}} / d t$ (black right triangles) in $\left\{\mathrm{A}_{\mathrm{ML}}, \mathrm{B}_{\mathrm{ML}}, \mathrm{C}_{\mathrm{ML}}\right\}$ represent multiple growing baroclinic eddies within the mixed layer front.

scale considered, and thus $\psi^{*}$ has a meridional extension limited to the Nordic flank of the ridge. On the other hand, MLEs promote a residual overturning circulation $\psi^{*}$ in the temperature range associated with the mixed layer front (Figs. 13b,d,f), and promote a rapid restratification of the mixed layer, by advecting warm surface temperature anomalies northward. The circulation $\psi^{*}$ does not reach across the outcropping thermocline; instead, it is confined meridionally south of the location of the mean jet where the most unstable MLEs dominate the evolution of the front.

\section{Implications for the Iceland-Faeroe Front}

Eddies resulting from the instability of topographically locked rim currents that circle around convective basins play an important role in the water mass transformation at high latitudes, a central process in global climate (Spall 2004). Eddies that separate from baroclinic currents carry heat that is deposited far away from their generation site, near deep convection sites, providing the necessary heat to close the heat budget associated with basin-scale convective overturning (Spall 2010). The topographically locked IFF is the widest and shallowest open ocean boundary separating the North Atlantic from the Nordic Seas, and thus regulates the inflow of warm water across the IFR into the convective Nordic basins. The eddies that are generated along the IFF, on the other hand, advect heat across the front and therefore play an important role in regulating the amount of water that is exchanged between the Nordic Seas and the subpolar North Atlantic. In this section we address the relative importance of eddies resulting from baroclinic instability of the modeled polar front. 


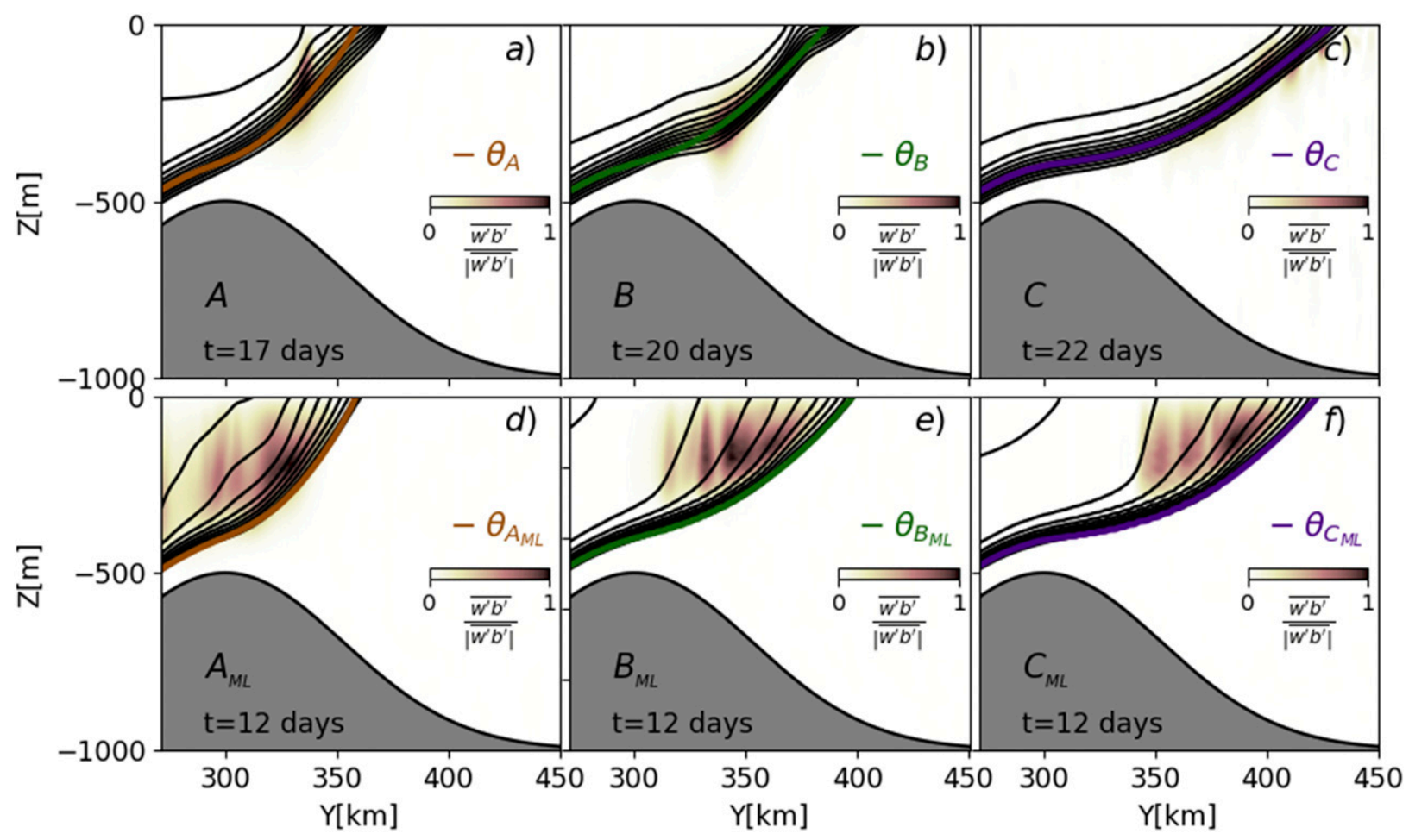

FIG. 11. Spatial distribution across the domain shown in Fig. 6 of normalized buoyancy production $\mathbf{C}_{\mathrm{EA}}$ for all simulations, at a later time after linear growth. Black contours represent mean temperature $\bar{T}$, with $0.5^{\circ} \mathrm{C}$ increments. Maximum values attained for experiments $\{A, B, C\}$ are associated with the thermocline, while those for experiments $\left\{A_{M L}, B_{M L}, C_{M L}\right\}$ vary spatially, signaling the presence of multiple growing eddies over the frontal region.

To provide a measure of the role of the eddies on the exchange under the two frontal configurations in this study $\left(\{\mathrm{A}, \mathrm{B}, \mathrm{C}\}\right.$ and $\left.\left\{\mathrm{A}_{\mathrm{ML}}, \mathrm{B}_{\mathrm{ML}}, \mathrm{C}_{\mathrm{ML}}\right\}\right)$, we compare the advective eddy heat flux to the mean heat advection by the zonal surface jet, which represents the flux of Atlantic waters into the Nordic basin. In the model, the along-ridge (northward, since the mean flow that is along topographic contours heads northward, once it flows past the IFR as in Fig. 1) flux of Atlantic waters by the mean flow is $Q_{\mathrm{FB}} \approx 3 \mathrm{~Sv}\left(1 \mathrm{~Sv} \equiv 10^{6} \mathrm{~m}^{3} \mathrm{~s}^{-1}\right)$, close to that observed in yearlong averages (Hansen et al. 2008). The associated advective heat flux is given by $\mathscr{H}_{\mathrm{FB}}=$ $\rho_{0} c_{p} Q_{\mathrm{FB}} \Delta T \approx 80 \mathrm{TW}$, a factor of 2 smaller than that found during typical summertime conditions in observations (Rossby and Flagg 2012) [in the above flux calculation, $\rho_{0}=1025 \mathrm{~kg} \mathrm{~m}^{-3}, c_{P}=3580 \mathrm{~J} \mathrm{~kg}^{-1}{ }^{\circ} \mathrm{C}^{-1}$, and $\left.\Delta T=6^{\circ} \mathrm{C}\right]$. The advective eddy heat flux $\mathscr{H}_{\text {adv }}$, given by

$$
\mathscr{H}_{\mathrm{adv}}=L_{x} \rho_{0} c_{p} \int_{z=-h}^{z=\eta} \overline{v^{\prime} T^{\prime}} d z,
$$

is greatest when the instability of the front becomes nonlinear, characterized in $\{\mathrm{A}, \mathrm{B}, \mathrm{C}\}$ by isolated cold anomalies that pinch off from the main front (Fig. 14).
The location of the maximum $\mathscr{H}_{\mathrm{adv}}$ with respect to bottom topography closely matches the averaged meridional location of the isolated eddy cores, each with length scale $\lambda^{e} \approx 12 \mathrm{~km}$. The maximum eddy heat flux is $\mathscr{H}_{\mathrm{adv}} \approx 50 \mathrm{TW}$, a value comparable to that of the mean $\mathscr{H}_{\mathrm{FB}}$ (Fig. 14a). When averaged over the upper $500 \mathrm{~m}$ and over the length of the ridge, the eddy heat flux gives the upper bound maximum intensity of around $40 \times 10^{4} \mathrm{~W} \mathrm{~m}^{-2}$, a value that agrees well with recent observational estimates (Beaird et al. 2016). In comparison, the maximum eddy heat flux calculated for $\left\{\mathrm{A}_{\mathrm{ML}}, \mathrm{B}_{\mathrm{ML}}, \mathrm{C}_{\mathrm{ML}}\right\}$ over the time scale $T_{\mathrm{adv}}$ is $\mathscr{H}_{\mathrm{adv}} \approx$ $17 \mathrm{TW}$, which corresponds to $13.6 \times 10^{4} \mathrm{~W} \mathrm{~m}^{-2}$ when averaged over the upper $500 \mathrm{~m}$ and the length of the ridge (Fig. 14d). The difference in the maximum eddy heat flux recorded from the eddies in $\{\mathrm{A}, \mathrm{B}, \mathrm{C}\}$ and those in $\left\{\mathrm{A}_{\mathrm{ML}}, \mathrm{B}_{\mathrm{ML}}, \mathrm{C}_{\mathrm{ML}}\right\}$ is associated with the eddy temperatures anomalies $T^{\prime}$, and these are much larger for eddies in $\{\mathrm{A}, \mathrm{B}, \mathrm{C}\}$. In addition, we find that the eddy heat flux is dependent on the sloping bottom, with the greater values resulting from the more destabilizing bottom topography ( $\gamma_{\mathrm{NO}}$ less negative) when the frontal jet is located closer to the ridge crest, and the lesser values associated with less destabilizing bottom topography 

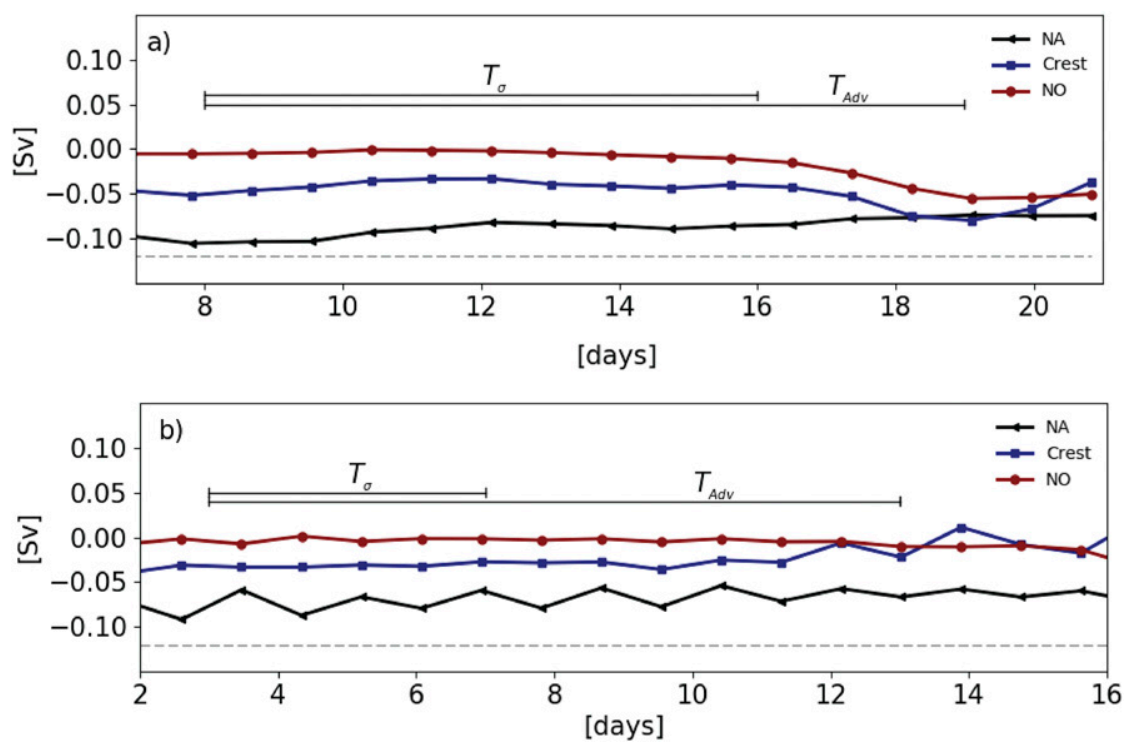

FIG. 12. Bottom Ekman transport $V_{\mathrm{Ek}}$ for (a) experiment $\mathrm{A}$ and (b) experiment $\mathrm{A}_{\mathrm{ML}}$ computed at three locations: at the core of the bottom-intensified jet (dotted black, denoted NA), at the crest of the ridge (dotted blue, denoted Crest), and at the location of the maximum bottom current on the Nordic flank of the ridge (dotted red, denoted NO) that is associated with the surface intensified jet. The gray line represents the estimate transport given in Beaird et al. (2013) of $V_{\mathrm{Ek}}=-0.12 \mathrm{~Sv}$, where $V_{\mathrm{Ek}}<0$ represents southward flow.

$\left(\gamma_{\mathrm{NO}}\right.$ more negative), that is, frontal jet located over deeper waters.

In experiments $\{\mathrm{A}, \mathrm{B}, \mathrm{C}\}$, within the time scales considered, the isolated anomalies did not reach across the ridge crest onto the Atlantic flank. Thus, the anomalies will likely get advected downstream by the mean flow, which roughly follows topographic contours. Eddies that originate closer to the ridge crest, and where the front is steeper (as in A), will be more likely to cross. These conditions are usually met on the western end of the IFF, closer to Iceland (Maskell et al. 1992). In contrast, eddies in simulations $\left\{\mathrm{A}_{\mathrm{ML}}, \mathrm{B}_{\mathrm{ML}}, \mathrm{C}_{\mathrm{ML}}\right\}$ grow over the entire mixed layer baroclinic zone, with their initial growth not significantly affected by depth changes below $\theta$. Whether these eddies can induce a residual circulation that reaches across the IFR initially depends on the extent of the mixed layer frontal zone, and later on the background characteristics of the frontal zone, as detailed in Manucharyan and Timmermans (2013). Given the relatively shallow polar front that sits over the IFR and the deep wintertime convection that takes place over the region, where observations show mixed layer depths on the order of $500 \mathrm{~m}$ over the IFR in winter (Beaird et al. 2016), it is likely that mixed layer frontal zones exist and extend across the crest of the IFR.

MLEs all originate within warm temperature classes (warmer temperatures than $\theta$ ) where the mixed layer front is unstable. Thus, at least during their initial growth, while MLEs advect heat laterally (Fig. 14b), they do not necessarily advect heat across the mean $\theta$ contour, which represents the barrier between Atlantic and Nordic waters, as seen from the residual overturning circulation (Fig. 13). As MLEs restratify the mixed layer south of the main outcropping IFF, MLEs can flux surface ocean properties downward and, depending on the strength of surface cooling, can even shut down convection (Callies and Ferrari 2018). Eddies in experiment B induce strong vertical buoyancy and heat flux once the isolated eddies form that are linked to frontal collapse and the strong lateral temperature gradients around the isolated anomalies (Fig. 15). Eddies in $\mathrm{B}_{\mathrm{ML}}$, on the other hand, promote a strong surface vertical heat flux localized to the mixed layer front. The vertical heat flux associated with the MLEs grows exponentially during the initial growth, but equilibrates after that, when it becomes comparable to values expected during wintertime $\sim O(100) \mathrm{W} \mathrm{m}^{-2}$ (Marshall and Schott 1999). This means that vertical heat flux driven by MLEs can become, during the time scales relevant for the IFF, an important process for the heat budget within the mixed layer, potentially balancing surface heat fluxes.

Our results also suggest that the evolution of the IFF in winter will most likely be characterized by both mixed layer eddies and mesoscale eddies. That is, wintertime 

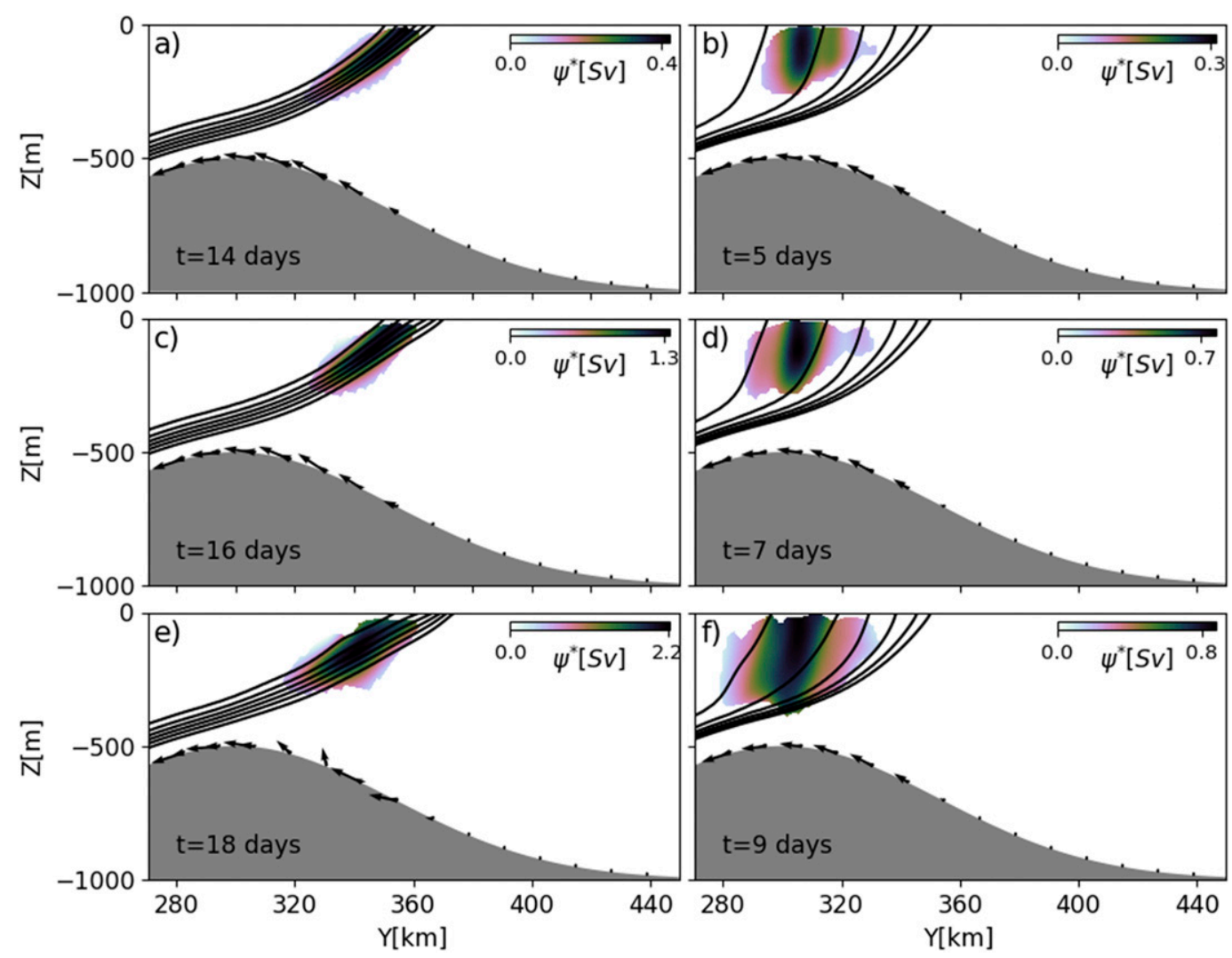

FIG. 13. Sequence of (eddy induced) overturning circulation $\psi^{*}$ for simulations (a),(c),(e) A and (b),(d),(f) $A_{M L}$. Here, $\psi^{*}$ is calculated by time-averaging the terms in (7) over a window of 2 days and considering only eddy heat fluxes above or greater than $10 \%$ of the maximum $\overline{w^{\prime} T^{\prime}}$. The arrows represent the mean cross-slope bottom transport $(\bar{v}, \bar{w})$, scaled by the aspect ratio of the figure to show the true direction. The dark contours represent the mean isotherms, plotted in $0.75^{\circ} \mathrm{C}$ intervals for experiment $\mathrm{A}$ and $0.5^{\circ} \mathrm{C}$ intervals for experiment $\mathrm{A}_{\mathrm{ML}}$, all averaged over a 2-day window.

conditions will most likely present a complex geography of baroclinic instability with isolated cold-core eddies that detach from the outcropping frontal thermocline and propagate south toward the ridge crest, while at the same time MLEs will grow in regions with deep mixed layers in the presence of baroclinicity. Meandering of the front associated with full-depth baroclinic waves like the ones in the experiments $\{\mathrm{A}, \mathrm{B}, \mathrm{C}\}$ are more likely to be responsible for promoting an increase of deep overflow across the IFR and cross-front exchange of between the North Atlantic and Nordic waters. MLEs, once reaching finite amplitude, are likely associated with lateral stirring of water that promotes cross-ridge spreading of water mass. The rapid MLE growth could make lateral stirring within the mixed layer a dominant mechanism of cross-ridge exchange of surface water masses, while the meandering of the front remains an important mechanism yearlong for cross-frontal exchange, with implications for bottom overflow transport.

\section{Limitations and conclusions}

We investigated the effects of bottom topography on the baroclinic instability of an idealized representation of the IFF, motivated by contrasting temperature distributions that represent summer and wintertime conditions. The dynamics of all simulations are eddy dominated, with two different regimes of surface intensified baroclinic instability. The first is a mesoscale instability characterized by a temperature distribution with no surface mixed layer typical of a shallow summer mixed layer as represented in experiments $\{\mathrm{A}, \mathrm{B}, \mathrm{C}\}$, and in which both the slope parameter and depth ratio play a role on the stability of the frontal configuration. We find the greater growth rates for the most destabilizing values of slope parameter experiences by the jet in our study (i.e., the less negative $\gamma_{\mathrm{NO}}$ ), in accordance to linear stability analysis of the modified Eady model. The estimated growth rates decrease as the baroclinic jet moves toward deeper water, hence an increase of the 

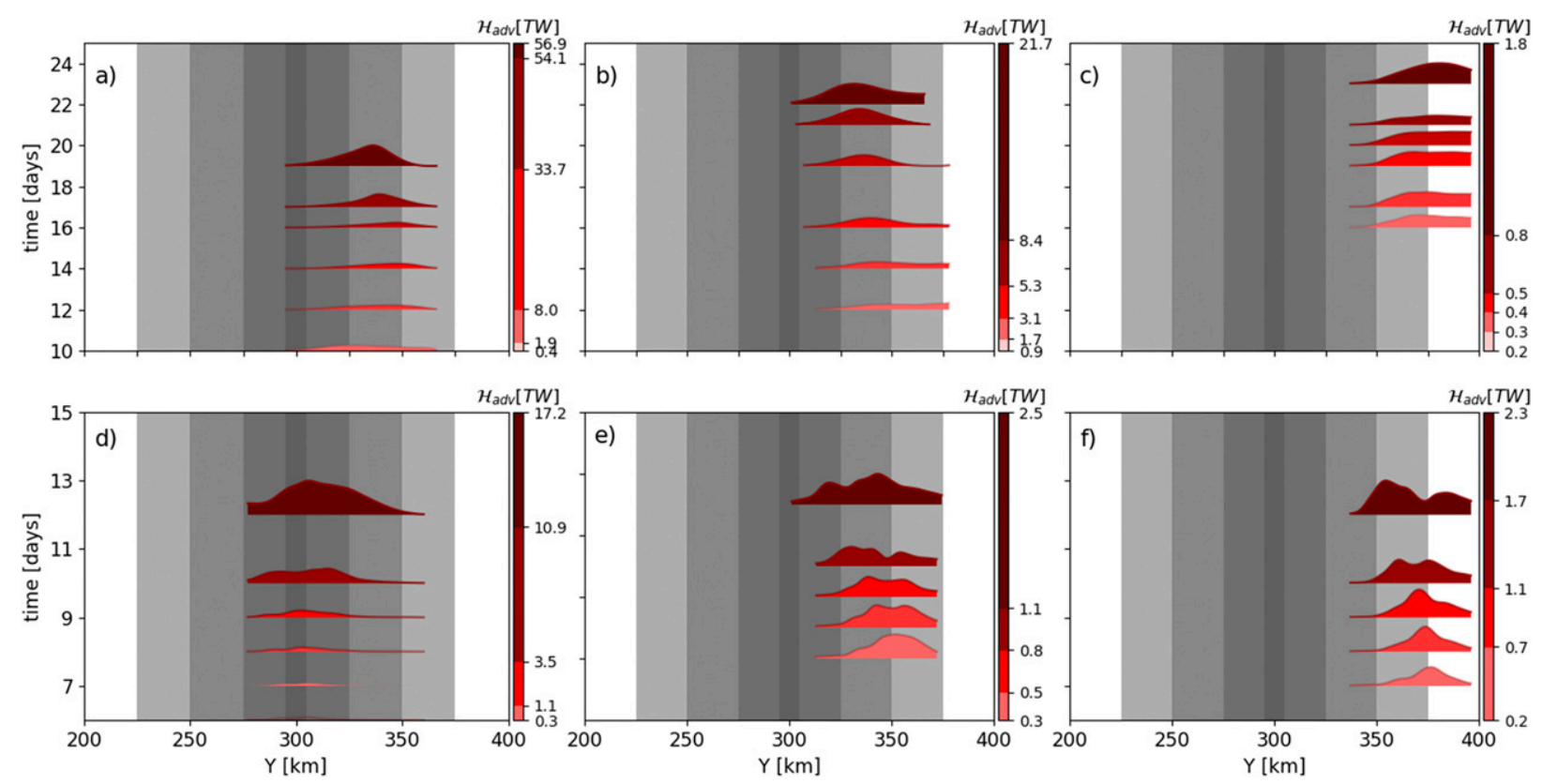

FIG. 14. Time evolution of the meridional distribution of the advective eddy heat flux $\mathscr{H}_{\text {adv }}$ in both (a)-(c) control experiments $\{\mathrm{A}, \mathrm{B}, \mathrm{C}\}$ and (d)-(f) experiments $\left\{\mathrm{A}_{\mathrm{ML}}, \mathrm{B}_{\mathrm{ML}}, \mathrm{C}_{\mathrm{ML}}\right\}$. At each time, the shape represents the spatial distribution with respect to bottom topography (gray-filled contours), and the color is associated with the maximum heat transport (the peak). Each spatial distribution is normalized with respect to the next, and each tick value on the discrete (red) color bar is spaced proportional to the jump in $\mathscr{H}_{\text {adv }}$.

depth ratio as well as the jet experiencing a more negative and therefore less destabilizing slope parameter compared to the other cases considered. Although this points to a good agreement on the expected behavior of growth rates with that of the theory, calculated growth rates were expectedly higher than the growth rates that theory predicts (by a factor of 2).

The second regime is that of a mixed layer instability characterized by MLEs that grow within the mixed layer front that are insensitive to the presence of bottom topography during initial growth of the instability, as represented in experiments $\left\{\mathrm{A}_{\mathrm{ML}}, \mathrm{B}_{\mathrm{ML}}, \mathrm{C}_{\mathrm{ML}}\right\}$. Sloping bottom topography does have an effect on these simulations once mixed layer eddies are already fully developed, by promoting a faster mesoscale eddy growth when the surface frontal jet sits atop the shallower and less negative bottom topographic slopes. Whether there is significant cross-scale, nonlinear energy flux between the mixed-layer and mesoscale modes, we do not address here. A major limitation in our analysis is the periodic domain, which constrains the time integrations, but not the growth rates, as we performed additional simulations (not shown here) varying the length of the channel with no effect on the calculated growth rates. Thus, we considered the results up to an advective time scale on the order of 10 days, much smaller that the damping time scale associated with air-sea fluxes, which is on the order of 1 month in high latitudes, which increases for increasing mixed-layer depth (Frankignoul et al. 1998).

Our results show eddy-driven cross-front lateral heat flux that is comparable to that by the mean flow $\left(\mathscr{H}_{\mathrm{FB}}\right)$, the latter depending directly on the temperature jump across the front (the strength of the geostrophic also depends on the temperature jump $\Delta T$ ). On the initialization of the experiments, we set the temperature jump $\sim 20 \%$ below to those of observational estimates, thus providing a lower bound estimate for $\mathscr{H}_{\mathrm{FB}}$, which helps explain a mean heat transport smaller than observational transport estimates. The initial amplitude of the perturbation that seeds the instability is the same for all our experiments, allowing direct comparison between simulations with and without a mixed layer front. The spatial scale of the initial (temperature) perturbation is the smallest scale $\left( \pm 0.2^{\circ} \mathrm{C}\right.$ every $\left.d x, d y\right)$, and by focusing on the initial development of the instability (i.e., from small amplitude) up to an advective (residence) time scale, we argue our estimates provide lower-bound estimates of the eddy heat transports as a function of time. The maximum of these (lower bound) estimates takes place when the baroclinic eddies have reached a finite amplitude and greatly distort the front, leading to coldcore eddies that pinch off from the front into warmer temperature waters. These greater transport estimates 


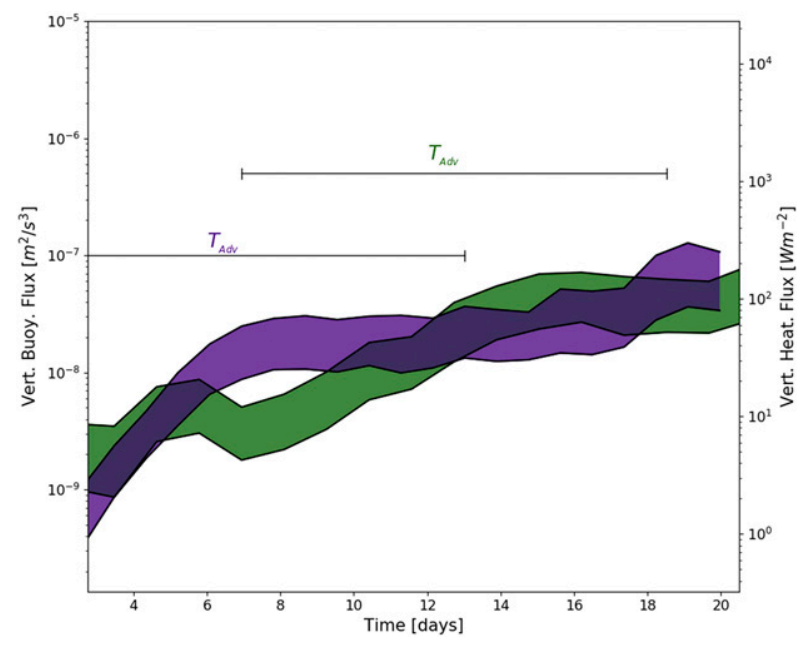

FIG. 15. Vertical buoyancy flux $\overline{w^{\prime} b^{\prime}}$ (left axis) and the equivalent surface vertical heat flux required to change the equivalent amount of buoyancy $c_{p} \rho_{0} \overline{w^{\prime} b^{\prime}} / g \alpha$ (right axis) for simulations B (green) and $\mathrm{B}_{\mathrm{ML}}$ (indigo).

are associated with eddy separation from the front and thus depend strongly on the $\Delta T$ across the front.

Another potential limitation for our study is the choice of depth for the mixed layer front. While at high latitudes wintertime mixed layer depth can reach $500 \mathrm{~m}$ (or deeper), the depth of a mixed layer front depends on the presence of baroclinicity and, in the case of the IFF, on the depth of the outcropping pycnocline. In our initial configuration the depth of the mixed layer front has a range of values $100 \mathrm{~m}<h_{\mathrm{ML}}<300 \mathrm{~m}$. It is possible that our simulations underestimate the depth of the mixed layer front, which can potentially affect our results, in particular by shifting the eddy advective transport estimates to larger values (since mixed layer eddies would be deeper). Thus, again, we argue that our heat transport calculations represent lower-bound estimates.

In this study, we find through our estimates that eddy dynamics that arise from the instability of the IFF have the potential to play an important role on lateral heat exchange across the region south and north of the IFR, with sloping topography playing a crucial role through the slope parameter, whether the initial development of eddies is dominated by mesoscale baroclinic instability or mixed layer instability.

Acknowledgments. This research was funded by NASA (NNX13AE28G, NNX13AH19G, and NNX17AH56G) and the Mexican Council for Science and Technology (CONACyT). We thank Nick Beaird and Peter Rhines for helpful discussions in the early stages of this study, and Paola Cessi, Jacob Wenegrat, and an anonymous reviewer for greatly improving our manuscript.

\section{APPENDIX}

\section{Analytical Expressions for Topography and Initial Temperature Conditions}

\section{a. Bottom topography}

Topography is constructed by matching two reference profiles in order to construct a symmetric ridge:

$$
h(y)=h_{\mathrm{NA}} \mathscr{H}\left(y-y_{0}\right)+h_{\mathrm{NO}} \mathscr{H}\left(y+y_{0}\right),
$$

where $\mathscr{H}$ is the Heaviside function centered at $y=y_{0}$, and $h_{\mathrm{NA}}, h_{\mathrm{NO}}$ are the topographic profiles on the southern and northern flanks, respectively. These are given by

$$
h_{\mathrm{NA}}=\frac{H_{0}}{2}+\Delta h\left[1-\tanh \left(\frac{y-y_{1}}{L_{T}}\right)\right],
$$

and

$$
h_{\mathrm{NO}}=H_{0}-\Delta h\left[1-\tanh \left(\frac{y-y_{2}}{L_{T}}\right)\right] \text {, }
$$

where $y_{1}, y_{2}$ center the respective topographic profiles, with $y_{1}<y_{0}<y_{2}$. Parameter $L_{T}$ sets the deformation scale of bottom topography at $y=y_{1}$ and $y=y_{2}$. Parameter $H_{0}=1000 \mathrm{~m}$ is the depth far away from the ridge and $\Delta h=250 \mathrm{~m}$ represents half the topographic amplitude.

\section{b. Temperature}

The initial temperature is constructed by matching two reference temperature distributions, associated with the southern and the northern flank of the ridge, respectively. That is,

$$
T(y, z)=T_{\mathrm{NA}} \mathscr{H}\left(y-y_{0}\right)+T_{\mathrm{NO}} \mathscr{H}\left(y+y_{0}\right),
$$

where $T_{\mathrm{NA}}$ represents the temperature on the southern flank. Temperature $T_{\mathrm{NA}}$ mimics bottom topography with the isotherms closely following the bottom sloping topography so that the slope parameter $\delta \rightarrow 1^{-}$(approaches 1 from negative values). Temperature $T_{\mathrm{NA}}$ is given by

$$
\begin{aligned}
T_{\mathrm{NA}} & =T_{0}+\Delta T \tanh \left[\frac{z+\mathscr{Z}_{1}(y)}{\delta h}\right], \\
\mathscr{Z}_{1}(y) & =1-\beta \tanh \left(\frac{y-y_{1}^{*}}{L_{f}}\right) .
\end{aligned}
$$

On the northern flank, the temperature front outcrops at the surface over the sloping bottom so that the slope parameter $\delta \rightarrow-1^{+}$(approaches -1 from positive 
values). On the northern flank, the temperature distribution $T_{\mathrm{NO}}$ is given by

$$
\begin{aligned}
T_{\mathrm{NO}}(y, z) & =T_{0}+\Delta T \tanh \left[\frac{z+\mathscr{E}_{2}(y)}{\delta h}\right], \\
\mathscr{\mathscr { E }}_{2}(y) & =\frac{1}{2}-\tanh \left(\frac{y-y_{2}^{*}}{L_{f}}\right) .
\end{aligned}
$$

\section{REFERENCES}

Allen, J., D. Smeed, and A. Chadwick, 1994: Eddies and mixing at the Iceland-Færæ Front. Deep-Sea Res. I, 41, 51-79, https:// doi.org/10.1016/0967-0637(94)90026-4.

Badger, J., and B. Hoskins, 2001: Simple initial value problems and mechanisms for baroclinic growth. J. Atmos. Sci., 58, 38-49, https://doi.org/10.1175/1520-0469(2001)058<0038: SIVPAM $>2.0 . \mathrm{CO} ; 2$.

Barth, J., 1989: Stability of a coastal upwelling front: 1. Model development and a stability theorem. J. Geophys. Res., 94 10 844-10 856, https://doi.org/10.1029/JC094iC08p10844.

Beaird, N., P. Rhines, and C. Eriksen, 2013: Overflow waters at the Iceland-Faroe Ridge observed in multiyear Seaglider surveys. J. Phys. Oceanogr., 43, 2334-2351, https://doi.org/10.1175/ JPO-D-13-029.1.

_ P. B. Rhines, and C. C. Eriksen, 2016: Observations of seasonal subduction at the Iceland-Faroe Front. J. Geophys. Res. Oceans, 121, 4026-4040, https://doi.org/10.1002/2015JC011501.

Blumsack, S. L., and P. Gierasch, 1972: Mars: The effects of topography on baroclinic instability. J. Atmos. Sci., 29, 1081-1089, https:// doi.org/10.1175/1520-0469(1972)029<1081:MTEOTO>2.0.CO;2.

Boccaletti, G., R. Ferrari, and B. Fox-Kemper, 2007: Mixed layer instabilities and restratification. J. Phys. Oceanogr., 37, 2228 2250, https://doi.org/10.1175/JPO3101.1.

Boss, E., N. Paldor, and L. Thompson, 1996: Stability of a potential vorticity front: from quasi-geostrophy to shallow water. J. Fluid Mech., 315, 65-84, https://doi.org/10.1017/S0022112096002339.

Brink, K. H., and S. J. Lentz, 2010: Buoyancy arrest and bottom Ekman transport. Part I: Steady flow. J. Phys. Oceanogr., 40, 621-635, https://doi.org/10.1175/2009JPO4266.1.

Callies, J., and R. Ferrari, 2018: Baroclinic instability in the presence of convection. J. Phys. Oceanogr., 48, 45-60, https:// doi.org/10.1175/JPO-D-17-0028.1.

_ G. Flierl, R. Ferrari, and B. Fox-Kemper, 2016: The role of mixed-layer instabilities in submesoscale turbulence. J. Fluid Mech., 788, 5-41, https://doi.org/10.1017/jfm.2015.700.

Condie, S. A., 1995: Descent of dense water masses along continental slopes. J. Mar. Res., 53, 897-928, https://doi.org/10.1357/ 0022240953212936.

Eady, E. T., 1949: Long waves and cyclone waves. Tellus, 1, 33-52, https://doi.org/10.3402/tellusa.v1i3.8507.

Eldevik, T., and K. B. Dysthe, 2002: Spiral eddies. J. Phys. Oceanogr., 32, 851-869, https://doi.org/10.1175/1520-0485(2002) 032<0851:SE $>2.0 . \mathrm{CO} ; 2$.

Flagg, C. N., and R. C. Beardsley, 1978: On the stability of the shelf water/slope water front south of New England. J. Geophys. Res., 83, 4623-4631, https://doi.org/10.1029/JC083iC09p04623.

Fox, A. D., and S. J. Maskell, 1996: A nested primitive equation model of the Iceland-Faeroe Front. J. Geophys. Res. Oceans, 101, 18 259-18 278, https://doi.org/10.1029/96JC01530.
Frankignoul, C., A. Czaja, and B. L'Heveder, 1998: Air-sea feedback in the North Atlantic and surface boundary conditions for ocean models. J. Climate, 11, 2310-2324, https://doi.org/ 10.1175/1520-0442(1998)011<2310:ASFITN>2.0.CO;2.

Hansen, B., and J. Meincke, 1979: Eddies and meanders in the Iceland-Faroe Ridge area. Deep-Sea Res., 26A, 1067-1082, https://doi.org/10.1016/0198-0149(79)90048-7.

— , S. Østerhus, W. R. Turrell, S. Jónsson, H. Valdimarsson, H. Hátún, and S. M. Olsen, 2008: The inflow of Atlantic water, heat, and salt to the Nordic Seas across the GreenlandScotland Ridge. Arctic-Subarctic Ocean Fluxes, Springer, 15-43, https://doi.org/10.1007/978-1-4020-6774-7_2.

Heifetz, E., P. Alpert, and A. Da Silva, 1998: On the parcel method and the baroclinic wedge of instability. J. Atmos. Sci., 55, 788-795, https://doi.org/10.1175/1520-0469(1998) 055<0788:OTPMAT $>2.0 . \mathrm{CO} ; 2$.

Hetland, R. D., 2017: Suppression of baroclinic instabilities in buoyancy-driven flow over sloping bathymetry. J. Phys. Oceanogr., 47, 49-68, https://doi.org/10.1175/JPO-D-15-0240.1.

Isachsen, P. E., 2011: Baroclinic instability and eddy tracer transport across sloping bottom topography: How well does a modified Eady model do in primitive equation simulations? Ocean Modell., 39, 183-199, https://doi.org/ 10.1016/j.ocemod.2010.09.007.

Lozier, M. S., and M. S. Reed, 2005: The influence of topography on the stability of shelfbreak fronts. J. Phys. Oceanogr., 35, 10231036, https://doi.org/10.1175/JPO2717.1.

MacCready, P., 1994: Frictional decay of abyssal boundary currents. J. Mar. Res., 52, 197-217, https://doi.org/10.1357/ 0022240943077073.

Manucharyan, G. E., and M.-L. Timmermans, 2013: Generation and separation of mesoscale eddies from surface ocean fronts. J. Phys. Oceanogr., 43, 2545-2562, https://doi.org/10.1175/ JPO-D-13-094.1.

Marshall, J., and F. Schott, 1999: Open-ocean convection: Observations, theory, and models. Rev. Geophys., 37, 1-64, https:// doi.org/10.1029/98RG02739.

Maskell, S., A. Heathershaw, and C. Stretch, 1992: Topographic and eddy effects in a primitive equation model of the IcelandFaeroes Front. J. Mar. Syst., 3, 343-380, https://doi.org/ 10.1016/0924-7963(92)90010-6.

Miller, A. J., P.-M. Poulain, A. Warn-Varnas, H. G. Arango, A. R. Robinson, and W. G. Leslie, 1995: Quasigeostrophic forecasting and physical processes of Iceland-Faroe frontal variability. J. Phys. Oceanogr., 25, 1273-1295, https://doi.org/ 10.1175/1520-0485(1995)025<1273:QFAPPO > 2.0.CO;2.

Pedlosky, J., 2013a: Geophysical Fluid Dynamics. Springer, 710 pp. , 2013b: Waves in the Ocean and Atmosphere: Introduction to Wave Dynamics. Springer, $264 \mathrm{pp}$.

Plumb, R. A., and R. Ferrari, 2005: Transformed Eulerian-mean theory. Part I: Nonquasigeostrophic theory for eddies on a zonal-mean flow. J. Phys. Oceanogr., 35, 165-174, https:// doi.org/10.1175/JPO-2669.1.

Prater, M. D., and T. Rossby, 2005: Observations of the Faroe Bank Channel overflow using bottom-following RAFOS floats. Deep-Sea Res. II, 52, 481-494, https://doi.org/10.1016/ j.dsr2.2004.12.009.

Quadfasel, D., and R. Käse, 2013: Present-day manifestation of the Nordic Seas overflows. Ocean Circulation: Mechanisms and Impacts-Past and Future Changes of Meridional Overturning, Geophys. Monogr., Vol. 173, Amer. Geophys. Union, 75-89.

Reszka, M. K., G. E. Swaters, and B. R. Sutherland, 2002: Instability of abyssal currents in a continuously stratified ocean with 
bottom topography. J. Phys. Oceanogr., 32, 3528-3550, https:// doi.org/10.1175/1520-0485(2002)032<3528:IOACIA > 2.0.CO;2.

Rossby, T., and C. Flagg, 2012: Direct measurement of volume flux in the Faroe-Shetland Channel and over the Iceland-Faroe Ridge. Geophys. Res. Lett., 39, L07602, https://doi.org/10.1029/ 2012GL051269.

Samelson, R., and D. Chapman, 1995: Evolution of the instability of a mixed-layer front. J. Geophys. Res., 100, 6743-6759, https://doi.org/10.1029/94JC03216.

Shchepetkin, A. F., and J. C. McWilliams, 2005: The Regional Oceanic Modeling System (ROMS): A split-explicit, free-surface, topography-following-coordinate oceanic model. Ocean Modell., 9, 347-404, https://doi.org/10.1016/j.ocemod.2004.08.002.

Simmons, A. J., and B. J. Hoskins, 1978: The life cycles of some nonlinear baroclinic waves. J. Atmos. Sci., 35, 414-432, https:// doi.org/10.1175/1520-0469(1978)035<0414:TLCOSN>2.0.CO;2.

Skyllingstad, E. D., and R. Samelson, 2012: Baroclinic frontal instabilities and turbulent mixing in the surface boundary layer. Part I: Unforced simulations. J. Phys. Oceanogr., 42, 17011716, https://doi.org/10.1175/JPO-D-10-05016.1.

Small, R. J., and Coauthors, 2014: A new synoptic scale resolving global climate simulation using the community earth system model. J. Adv. Model. Earth Syst., 6, 1065-1094, https:// doi.org/10.1002/2014MS000363.

Spall, M. A., 2004: Boundary currents and watermass transformation in marginal seas. J. Phys. Oceanogr., 34, 1197-1213, https://doi.org/ 10.1175/1520-0485(2004)034<1197:BCAWTI>2.0.CO;2.
2010: Dynamics of downwelling in an eddy-resolving convective basin. J. Phys. Oceanogr., 40, 2341-2347, https://doi.org/ 10.1175/2010JPO4465.1.

Stewart, A., and A. Thompson, 2015: The neutral density temporal residual mean overturning circulation. Ocean Modell., 90, 4456, https://doi.org/10.1016/j.ocemod.2015.03.005.

Stone, P. H., 1966: On non-geostrophic baroclinic stability. J. Atmos. Sci., 23, 390-400, https://doi.org/10.1175/1520-0469(1966) $023<0390$ :ONGBS $>2.0 . \mathrm{CO} ; 2$.

Tandon, A., and C. Garrett, 1994: Mixed layer restratification due to a horizontal density gradient. J. Phys. Oceanogr., 24 1419-1424, https://doi.org/10.1175/1520-0485(1994)024<1419: MLRDTA $>2.0 . \mathrm{CO} ; 2$.

— and _- 1995: Geostrophic adjustment and restratification of a mixed layer with horizontal gradients above a stratified layer. J. Phys. Oceanogr., 25, 2229-2241, https:// doi.org/10.1175/1520-0485(1995)025<2229:GAAROA> 2.0.CO;2.

Vallis, G. K., 2017: Atmospheric and Oceanic Fluid Dynamics. Cambridge University Press, 745 pp.

Wåhlin, A., and G. Walin, 2001: Downward migration of dense bottom currents. Environ. Fluid Mech., 1, 257-279, https:// doi.org/10.1023/A:1011520432200.

Wenegrat, J. O., J. Callies, and L. N. Thomas, 2018: Submesoscale baroclinic instability in the bottom boundary layer. J. Phys. Oceanogr., 48, 2571-2592, https://doi.org/ 10.1175/JPO-D-17-0264.1. 